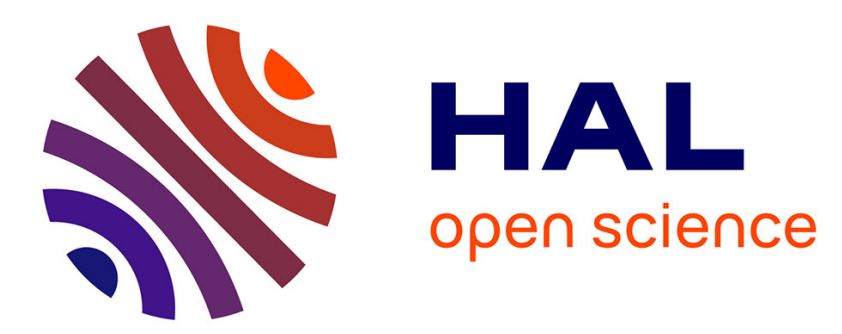

\title{
Residence Time Distributions in non-uniform aquifer recharge and thickness conditions - An analytical approach based on the assumption of Dupuit-Forchheimer
}

\author{
Sarah Leray, Alexandre Gauvain, Jean-Raynald de Dreuzy
}

\section{To cite this version:}

Sarah Leray, Alexandre Gauvain, Jean-Raynald de Dreuzy. Residence Time Distributions in nonuniform aquifer recharge and thickness conditions - An analytical approach based on the assumption of Dupuit-Forchheimer. Journal of Hydrology, 2019, 574, pp.110-128. 10.1016/j.jhydrol.2019.04.032 . insu-02094815

\section{HAL Id: insu-02094815 https://hal-insu.archives-ouvertes.fr/insu-02094815}

Submitted on 10 Apr 2019

HAL is a multi-disciplinary open access archive for the deposit and dissemination of scientific research documents, whether they are published or not. The documents may come from teaching and research institutions in France or abroad, or from public or private research centers.
L'archive ouverte pluridisciplinaire HAL, est destinée au dépôt et à la diffusion de documents scientifiques de niveau recherche, publiés ou non, émanant des établissements d'enseignement et de recherche français ou étrangers, des laboratoires publics ou privés. 


\section{Accepted Manuscript}

Research papers

Residence Time Distributions in non-uniform aquifer recharge and thickness conditions - An analytical approach based on the assumption of Dupuit-Forchheimer

Sarah Leray, Alexandre Gauvain, Jean-Raynald de Dreuzy

PII: S0022-1694(19)30364-6

DOI: https://doi.org/10.1016/j.jhydrol.2019.04.032

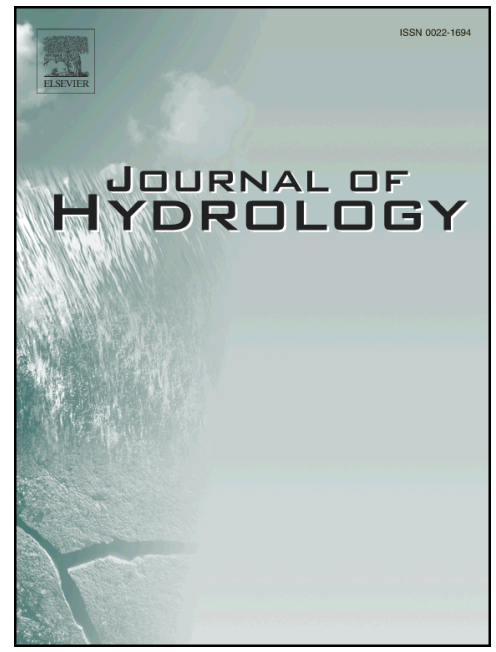

Reference:

HYDROL 23669

To appear in:

Journal of Hydrology

Received Date: $\quad 8$ January 2019

Revised Date: $\quad 4$ April 2019

Accepted Date: $\quad 8$ April 2019

Please cite this article as: Leray, S., Gauvain, A., de Dreuzy, J-R., Residence Time Distributions in non-uniform aquifer recharge and thickness conditions - An analytical approach based on the assumption of Dupuit-Forchheimer, Journal of Hydrology (2019), doi: https://doi.org/10.1016/j.jhydrol.2019.04.032

This is a PDF file of an unedited manuscript that has been accepted for publication. As a service to our customers we are providing this early version of the manuscript. The manuscript will undergo copyediting, typesetting, and review of the resulting proof before it is published in its final form. Please note that during the production process errors may be discovered which could affect the content, and all legal disclaimers that apply to the journal pertain. 


\section{Residence Time Distributions in non-uniform aquifer recharge and thickness conditions - An analytical approach based on the assumption of Dupuit-Forchheimer.}

Authors: Sarah Leray ${ }^{1,}{ }^{*}$, Alexandre Gauvain ${ }^{2}$, Jean-Raynald de Dreuzy ${ }^{3}$

${ }^{1}$ Departamento de Ingeniería Hidráulica y Ambiental, Pontificia Universidad Católica de Chile, Santiago, RM, Chile

${ }^{2}$ Univ Rennes, CNRS, Géosciences Rennes - UMR 6118, F-35000 Rennes, France

${ }^{3}$ Univ Rennes, CNRS, OSUR - UMS 3343, Geosciences Rennes - UMR 6118, F-35000 Rennes, France

*Corresponding author: sarah.leray1@gmail.com, saleray@ing.puc.cl

\section{Abstract}

Residence Times in aquifers result from their internal structure, from the hydrodynamic transport processes and from the recharge conditions to which they are exposed. Beyond the already known residence time distributions (RTD) for either constant aquifer thickness and/or uniform recharge, we investigate the effect of both distributed aquifer thickness and distributed recharge. We develop a semi-analytical approximation of the RTD for generic trapezoidal aquifers exposed to linearly-variable recharges. The solution is derived for a homogeneous $2 \mathrm{D}$ cross-sectional aquifer in steady-state conditions following the Dupuit-Forchheimer assumption according to which the vertical head gradients are much smaller than the horizontal head gradients. Close agreement with 2D numerical simulations demonstrates the relevance of the Dupuit-Forchheimer assumption to estimate RTDs as long as the aquifer thickness remains an order of magnitude smaller than the aquifer length. At equivalent aquifer volume, geometrical structure and recharge conditions result in non-trivial and complex RTD shapes that may be uniform, Gamma-like, power-law-like shapes as well as any 
intermediary shapes. The variety of RTD shapes encountered show the need to systematically include the aquifer structure and recharge conditions in the assessment of RTDs and for their subsequent use for problematics related to water quality. The semi-analytical approximation can be further used in a variety of aquifer systems in complement with other existing solutions as a Lumped Parameter Model for RTDs.

\section{Introduction}

Characterizing residence times in hydrologic systems is critical to both fundamental and applied issues of water quality and risk assessment. In groundwater systems, residence times range from a few days to several hundreds of thousands of years following the differences in permeability and aquifer structures (Cirpka and Kitanidis, 2001; Cook and Böhlke, 2000; Eberts et al., 2012; Koh et al., 2018; Luo and Kitanidis, 2004; Visser et al., 2013). Residence time distributions (RTDs) are fundamental intermediaries between geology, geochemistry and water quality (Leray et al., 2016). On one side, RTDs can be related to the geological structures, to the hydrodynamic forcing terms and flow patterns and to the transport of chemical species (Bethke and Johnson, 2002; Campana, 1987). On the other side, RTDs provide invaluable constraints on the fate of contaminants, on their dilution in the groundwater systems and on their potential degradation and transformation with time (Cook and Herczeg, 2000; Pinay et al., 2015).

Unlike geology or any chemical species, RTDs cannot be mapped or measured. Some of their characteristics can be determined by deconvoluting natural or anthropogenic tracer concentrations, providing essential indications on the range of residence times (Cook and Herczeg, 2000; Kazemi et al., 2005). Beyond these ranges, the shape of the RTDs cannot be measured. Shapes have been independently approached as the result of calibrated numerical models (Eberts et al., 2012; Ginn et al., 2009; McGuire and McDonnell, 2006) or postulated as analytical solutions that can be expressed on simplified aquifer cases (Amin and Campana, 1996; Małoszewski and Zuber, 1982). Such expressions explicitly relate the RTD to the aquifer structure. They are used as interpretation 
frameworks of measured tracer concentrations to predict the full RTD on the basis of reasonable assumptions of the aquifer structure. Even if they cannot be accurate as numerical models, they can be straightforwardly used to provide first estimates of the RTD.

Among the existing analytical expressions, the exponential model is among the simplest and most widely used solutions (Ivey et al., 2008; Knowles et al., 2010; Koh et al., 2006; Long and Putnam, 2006; Manning and Caine, 2007; Osenbrück et al., 2006; Solomon et al., 2010). It has been first obtained for a continuously stirred tank reactor (Danckwerts, 1953; Eriksson, 1958). Later it has been shown to be also the solution of the flows to a well in a $2 \mathrm{D}$ homogeneous aquifer under the assumption of vertical integration of flows (Dupuit-Forchheimer assumption) (Haitjema, 1995; Vogel, 1967). The exponential model is constrained by a unique parameter usually taken as the mean residence time (MRT). For both of the cases mentioned above, the MRT is equal to the volume divided by the renewal flux. In the $2 \mathrm{D}$ aquifer case, the volume can be expressed as the product of the porosity $\theta$ by the mean saturated thickness $H$ and the renewal flux by the recharge rate $R$ leading to the well-known MRT $\tau$ :

$$
\tau=\frac{\theta H}{R}
$$

As shown by equation 1 , both recharge and aquifer structure through the aquifer thickness determine the MRT although not independently. In unconfined aquifers for instance, because high recharge rates increase the saturated thickness, eventual compensations between saturated volume $(\theta H)$ and recharge $(R)$ occur (Haitjema and Mitchell-Bruker, 2005) without any systematic increase of the MRT. More generally, the MRT results from the interacting effects of topography, aquifer hydrodynamic properties and recharge patterns.

Most studies based on controlling factors of RTDs have so far focused on the effects of recharge rates, on their temporal and spatial evolutions related to orographic effects and climate change (Engdahl, 2017; Engdahl and Maxwell, 2015; Goderniaux et al., 2013; Jing et al., 2019; Maxwell et al., 
2016; Niu et al., 2017; Warrier et al., 2012). Comparatively fewer studies have explored the constrain of aquifer structures and their dependence on recharge facing the challenge of consistently incorporating them and their consequences on residence times (Cardenas, 2007; Chesnaux et al., 2005; Kolbe et al., 2016; Leray et al., 2012). Even more fundamentally, relating the shape of RTDs to aquifer structure requires some concepts of groundwater flow organizations. Topography-driven flow and transport have been historically organized in nested local, intermediary and regional circulation patterns (Cardenas, 2007; Tóth, 1963; Welch et al., 2012) resulting in multiple exponential or power-law RTDs (Goderniaux et al., 2013; Kirchner et al., 2001; Wang et al., 2016). While relevant for thick unconfined aquifers under high recharge rates, shallower systems result in stronger correlations between climate, geology and geomorphology to shape the organization of flows under free-surface controls uphill and topographic controls downhill (Bresciani et al., 2016a; Condon and Maxwell, 2015; Gleeson et al., 2011; Haitjema and Mitchell-Bruker, 2005). Consequences on RTDs remain to be investigated to establish the role of variable saturated thickness $(H)$ and recharge rate $(R)$. Aquifer response to transient forcing terms is another pressing challenge (Engdahl, 2017; Jing et al., 2019; Maxwell et al., 2016). Finally, it should be investigated to which extend RTDs can still be analytically approached by combining simple recharge and aquifer characteristics. While analytical models have first been derived from analytical solutions of the flow equations with various boundary and sampling conditions (Jurgens et al., 2016, 2012; Leray et al., 2016; Małoszewski and Zuber, 1982; Turnadge and Smerdon, 2014), RTD models have been extended to more general shapes known as Lumped Parameter Models including Lognormal and Gamma distributions and potentially SAS-STOP formalisms for transient evolutions. They are not per se solutions of the flow equation but their flexibility can approach a wide range of distributions found in theoretical and field studies (Botter et al., 2010; Kirchner, 2016; Małoszewski and Zuber, 1982; Velde et al., 2012).

In this study, we propose to investigate both the effects of aquifer structure and spatially-distributed recharge on RTDs through a semi-analytical solution of the flow equation. Aquifer structure is modelled as a 2D trapezoid shape. Recharge is linearly evolving along the aquifer. The solution is 
developed for homogeneous aquifer in steady-state conditions under the Dupuit-Forchheimer assumption, i.e. under dominant horizontal flows over vertical flows (Dupuit, 1863; Forchheimer, 1886). It extends previous developments for variable recharge or trapezoidal aquifers (Chesnaux et al., 2005; Etcheverry, 2001; IAEA, 2006; Leray et al., 2016). After deriving the analytical solution in section 2 , we analyse the shape of the resulting RTDs, relate them to the aquifer structure and recharge parameters and discuss their domain of validity (section 3). We eventually discuss their relevance to natural systems with respect to the main drivers of groundwater flow and transport (section 4).

\section{Model and Methods}

We successively state the assumptions made on aquifer structure and recharge conditions, the analytical developments and the numerical methods used for validation.

\subsection{Aquifer structure and recharge conditions}

First, the aquifer is uniform. Its porosity is noted $\theta[-]$. The aquifer is $2 \mathrm{D}$ cross-sectional, extending from its upstream to downstream limits at respectively $x=0$ and $x=L$ (Figure 1 ). The aquifer shape is assumed to be trapezoidal with a saturated thickness $H(x)$ linearly evolving with $x$ according to:

$$
H(x)=H_{0}+\frac{H_{L}-H_{0}}{L} x
$$

where $H_{L}$ and $H_{0}$ are its thicknesses [L] at its downstream and upstream limits, respectively.

Second, the recharge is imposed on its upper boundary according to the following linear function either increasing or decreasing towards the discharge zone:

$$
R(x)=R_{0}+\frac{R_{L}-R_{0}}{L} x
$$


where $R_{L}$ and $R_{0}$ are the recharge rate $\left[\right.$ L.T $\left.^{-1}\right]$ at the downstream and upstream boundaries, respectively. Third, the discharge occurs at the downstream limit considered as a head-imposed boundary condition. Fourth, it is assumed that the Dupuit-Forchheimer assumption holds with horizontal flows dominant over vertical flows. The head gradient is essentially horizontal resulting in a horizontal flow only function of $x$ and uniformly distributed over the aquifer thickness. Fifth, the solution is derived downstream at the aquifer outlet $(x=L)$, which captures every single flow line because of the Dupuit-Forchheimer approximation. Hence, the RTD results from the fully-mixed capture of the flow lines.

It should be noted that imposing recharge and saturation implicitly constrains the permeability and its evolution along the aquifer. For example, both increasing recharge and decreasing aquifer thickness from upstream to downstream concur to let permeability increase. Under these conditions, the flow equation does not have to be explicitly solved, enabling the transport equation to be explicitly solved for various aquifer and recharge conditions.

\subsection{Semi-Analytical derivation}

Through Dupuit-Forchheimer assumption, the flow $F$ is assumed to be essentially horizontal as a function of the position $x$ only:

$$
F(x)=\int_{0}^{x} R(u) d u=R_{0} x+\frac{R_{L}-R_{0}}{L} \frac{x^{2}}{2}
$$

The flow $F$ has a quadratic form increasing from 0 at the inlet up to $F_{L}=\frac{R_{L}+R_{0}}{2} L$ at $x=L$ (Figure 2a).

The transit time $t(x)$ from the recharge location $x$ to the outlet $L$ is obtained by integrating the inverse of pore velocity, i.e. the ratio of the flow $F$ to the porous thickness $\theta H$ : 


$$
t(x)=\int_{x}^{L} \theta \frac{1}{v(u)} d u=\theta \int_{x}^{L} \frac{H(u)}{F(u)} d u=\theta \int_{x}^{L} \frac{H_{0}+\frac{H_{L}-H_{0}}{l} u}{R_{0} u+\frac{R_{L}-R_{0} u^{2}}{L}} d u
$$

Decomposing the integrand into irreducible factors and integrating them lead to:

$$
\begin{gathered}
t(x)=\theta \int_{x}^{L} \frac{H_{0}}{R_{0}} \frac{1}{u}+\left(\frac{H_{L}-H_{0}}{L}-\frac{H_{0}}{R_{0}} \frac{R_{L}-R_{0}}{L} \frac{1}{2}\right) \frac{1}{R_{0}+\frac{R_{L}-R_{0}}{L} \frac{u}{2}} d u \\
t(x)=-\theta \frac{H_{0}}{R_{0}} \ln \left[\frac{x}{L}\right]+\theta\left(2 \frac{H_{L}-H_{0}}{R_{L}-R_{0}}-\frac{H_{0}}{R_{0}}\right) \ln \left[\frac{R_{L}+R_{0}}{2 R_{0}+\frac{R_{L}-R_{0}}{L} x}\right]
\end{gathered}
$$

The transit time $t(x)$ increases from downstream $(x=L)$ to upstream $(x=0)$. Indeed, when the recharge location is close to the outlet, the flow path length is infinitesimal, so does the transit time: $t(x=L)=0$. When the recharge location is next to the upstream boundary, the horizontal component of velocity itself tends to zero because of the impervious boundary condition and consequently the transit time diverges to infinity there: $\lim _{x \rightarrow 0} t(x)=+\infty$. The time $t(x)$ is thus a function of the hydrodynamic properties though $\theta$, of the recharge conditions through $R_{L}$ and $R_{0}$ and of the aquifer geometry through $H_{L}$ and $H_{0}$. It has a S-shaped form due to the logarithm function of eq. 6. (Figure $2 b$ ).

Using the dimensionless terms $x^{*}=\frac{x}{L}\left(x^{*} \in[0,1]\right)$ and $t^{*}=\frac{t}{\tau^{\prime}}$, where $\tau$ is the MRT expressed as:

$$
\tau=\theta \frac{H_{0}}{R_{0}} \frac{C_{H}+1}{C_{R}+1}
$$

where $C_{R}=\frac{R_{L}}{R_{0}}$ and $C_{H}=\frac{H_{L}}{H_{0}}$ are two dimensionless ratios characterizing the aquifer structure and recharge conditions, $t^{*}\left(x^{*}\right)$ can be derived from eq. 6 and solely expressed as a function of these two dimensionless ratios:

$$
t^{*}\left(x^{*}\right)=-\frac{C_{R}+1}{C_{H}+1} \ln \left[x^{*}\right]+\frac{C_{R}+1}{C_{H}+1}\left(2 \frac{C_{H}-1}{C_{R}-1}-1\right) \ln \left[\frac{C_{R}+1}{2+\left(C_{R}-1\right) x^{*}}\right]
$$


As $t^{*}$ and $x^{*}$ are independent variables, we can express the RTD as a function of the probability distribution of the recharge location $p\left(x^{*}\right)$ :

$$
p\left(t^{*}\right)=p\left(x^{*}\right)\left|\frac{d x^{*}}{d t^{*}}\right|
$$

The distribution of the recharge location, noted $p\left(x^{*}\right)$, is directly derived from the flow and varies linearly with $x^{*}$ from $x^{*}=0$ to $x^{*}=1$ (Figure $2 c$ ):

$$
p\left(x^{*}\right)=\frac{R(\mathrm{u})}{\int_{x^{*}=0}^{x^{*}=1} R(u) d u}
$$

The derivative of the recharge location $x^{*}$ with the residence time $\frac{d x^{*}}{d t^{*}}$ (Figure $2 \mathrm{~d}$ ) is obtained by deriving eq. 9 with respect to $x^{*}$ and by taking the inverse:

$$
\frac{d x^{*}}{d t^{*}}=\left(\frac{d t^{*}}{d x^{*}}\right)^{-1}=-\frac{C_{H}+1}{C_{R}+1} \times \frac{x^{*}}{2} \times \frac{2+\left(C_{R}-1\right) x^{*}}{1+\left(C_{H}-2\right) x^{*}}
$$

Because the relation $x^{*}\left(t^{*}\right)$ is non-linear and complex, it cannot be obtained analytically. $\frac{d x^{*}}{d t^{*}}$ and then $p\left(t^{*}\right)$ cannot be explicitly stated as a function of $t^{*} \cdot x^{*}\left(t^{*}\right)$ is consequently derived numerically using root finding algorithms - e.g. fzero of Matlab $^{\circledR}$ (MATLAB and Statistics Toolbox, 2012) or fsolve of SciPy in Python language (Jones et al., 2001; Millman and Aivazis, 2011; Oliphant, 2007). This step makes the derivation semi-analytical and not fully analytical. Figure $2 \mathrm{e}$ displays the resulting residence time distribution $p(t)$. The RTD has a non-trivial form resulting from the complex interplay of recharge conditions and aquifer structure.

\subsection{Numerical methods}

Numerical simulations for validating the analytical developments have been performed for confined aquifers with the same structure and boundary conditions. Aquifers have been uniformly discretized both horizontally and vertically to test the vertical integration of the Dupuit-Forchheimer assumption. Flow simulations have been performed with the finite difference methods implemented 
in Modflow (Harbaugh et al., 2017). Mesh resolutions are 1,000 and 50 in the horizontal and vertical directions. A mean ratio of aquifer depth to aquifer length of $1 / 10$ has been chosen. The smaller this aspect ratio, the more relevant is the Dupuit-Forchheimer assumption (Bresciani et al., 2016b; Haitjema, 2006, 1987). Residence times have been derived with Modpath from 1,000 particles uniformly injected over the top boundary of the aquifers and weighted according to the local recharge in a postprocessing step (Pollock, 2016). Numerical RTDs are finally obtained by building the histogram of the residence times for the entire set of particles. Complementary simulations have been performed for higher aspect ratios and unconfined aquifers to investigate possible extensions of the proposed approach. In unconfined conditions, simulations have been performed with the same upstream and downstream boundary conditions, the same discretization and the same porosity, and with a permeability of $10^{-5} \mathrm{~m} / \mathrm{s}$.

\section{Results}

The semi-analytical solutions are first compared to numerical simulations to assess the quality of the analytical approximations. Parametric studies are further performed on the validated semi-analytical solutions to investigate the moments and the shape of the distributions.

\subsection{Validation of the semi-analytical RTDs against numerical simulations}

The semi-analytical solutions of equations 6 and 10 for the residence time function of the recharge location and the RTD have been tested against numerical simulations performed as detailed in section 2.3 within the $\left(C_{H}, C_{R}\right)$ parameters space. To illustrate the validity of the solution, we present four cases where both recharge and thickness simultaneously vary. $C_{H}$ and $C_{R}$ are either equal to 0.1 or 10 leading to the case presented in Figure 3 and three other cases in Figure A1 in Appendices. In all cases, analytical and numerical solutions are close both for the recharge position versus residence time relation $t^{*}=f\left(x^{*}\right)$ (Figure 3a and each a) in Figure $\mathrm{A} 1$ ) and for the RTD (Figure $3 \mathrm{~b}$ and each $\mathrm{b}$ ) 
in Figure A1). Some numerical imprecisions are observed but are not significant to alter the predominance of horizontal flows over vertical flows (each e) in Figure A1).

The assumption of the semi-analytical approximation according to which flow lines are horizontal is however not respected. Flow lines obtained numerically are indeed not horizontal as shown by the flowlines pattern of Figure 3c (and each c) in Figure A1). Some curvature is observed because of the shape of the aquifer and of the specific boundary conditions (upper recharge and lateral discharge), as previously pointed out by Raats (1977). Despite this curvature, the time-coloured flow paths show mainly horizontal or sub-horizontal isochrones. Only slight deviations are observed, either upstream (cases $A$ and $B$ ) or downstream (cases $C$ and $D$ ) of the system. More importantly, the horizontal component of the velocity appears mainly constant over any vertical section. It is not stratified and depends only on the distance to the outlet (Figure $3 \mathrm{~d}$ and each $\mathrm{d}$ ) in Figure A1). It is also one to two orders of magnitude larger than the vertical component with only marginal possibilities to vary vertically to respect the flow continuity equation. With much smaller values, the vertical velocity varies much more with the depth $H^{*}$ and position $x^{*}$ following the constraints imposed by the evolving aquifer thickness and the boundary conditions (Figure $3 e$ and each e) in Figure A1).

The relatively smaller vertical velocity comes from the assumption of the relatively thin aquifer. In fact, we further tested the solution for an aspect ratio closer to 1 (cases E and F of Figure B. 1 in Appendices). For such higher but unrealistic aspect ratios, the analytical approximation diverges from the numerical solution. The uniformity of the horizontal velocity is no longer guaranteed and the vertical velocity tends to be as important as the horizontal velocity. When the aspect ratio remains smaller than $1 / 10$ as used here for most simulations, the residence time from the inlet to the outlet is driven by the recharge location which can be explicitly related to the depth of the flow line. The assumption of vertical integration at the root of the flow equation of Dupuit-Forchheimer holds for the advective transport conditions investigated. The relation $t^{*}=f\left(x^{*}\right)$ proposed in eq. 9 , and all the following equations, can be taken as valid approximations. 
We have further confirmed that the key assumption is the small aspect ratio by investigating unconfined aquifer cases. Numerical simulations of unconfined conditions indeed show that the analytical approximation remains valid as long as the head differences remains moderate in comparison to the thickness of the aquifer with no significant differences between the linear and parabolic free surface shapes of the analytical and numerical solutions (case A of Figure 3 and case $G$ of Figure C. 1 in Appendices). When free surface gets more convex, times tend to be systematically underestimated by the analytical approximation as a result of the linear free-surface assumption (cases $\mathrm{H}$ and I of Figure C. 1 in Appendices). It might be partially corrected by generalizing the semianalytical approach to parabolic aquifer profiles.

\subsection{Shapes and typology of RTDs}

The four cases presented in Figure 3 and Figure A1 show marked differences between RTDs, evolving from a peaked unimodal distribution for case A to widely distributed functions for cases B or C. Systematic sampling of the aquifer thickness and recharge conditions in the $C_{H}$ and $C_{R}$ parameter space confirms the broad range of RTDs and the strong impact of both factors, consistently with previous studies (Basu et al., 2012; Engdahl and Maxwell, 2015; Jing et al., 2019; Maxwell et al., 2016). Rather than the RTD itself, we display the product of the RTD with the MRT, $\tau p\left(t^{*}\right)$, as a function of the normalized residence time $t^{*}$ to highlight the range of time scales spanned by the distributions, the proportion of water types (young, intermediate, old...) and their different shapes.

Because the parameter space covered is large, over six orders of magnitude, we display the RTDs for a few emblematic cases only and evidence how modifications of the RTD shape follow the aquifer structure and recharge conditions. Figures 4a-c show normalized RTDs for three recharge patterns (constant, strongly decreasing downstream, strongly increasing downstream) with varying aquifer thicknesses, from the highest $C_{H}$ to the lowest ones. Figures $4 \mathrm{~d}$-f similarly show normalized RTDs for three emblematic aquifer structures (uniform, converging and diverging) with varying recharge patterns, from the highest $C_{R}$ to the lowest ones. 
A downstream-pinched aquifer, i.e. a converging aquifer, tends to generate younger water than an aquifer of constant thickness. Converging flow lines let velocity increase so as to maintain the overall flow rate and consequently reduce residence times. Figure $4 \mathrm{~b}$ shows such structural effects for a uniformly recharged aquifer. While decreasing $C_{H}$, the probability of occurrence of times smaller than the MRT - in short, young water - strongly increases as also shown by Etcheverry (2001) and Leray et al. (2016). The resulting RTD exhibits a power-law-like shape with less probable short times and a longer tail (purple curve of Figure $4 \mathrm{~b}$ ) than with the exponential model (black curve of Figure 4b). Inversely, an upstream-pinched aquifer, i.e. a diverging aquifer, tends to enhance the proportion of older water while slowing down flow upstream comparatively to an aquifer of constant thickness. In such diverging aquifers, where $C_{H} \gg 1$, the RTD is thus close to a uniform distribution (black dashdot curve of Figure 4b), known as the linear model (IAEA, 2006; Małoszewski and Zuber, 1982).

Recharge gradients have qualitatively similar effects. Increased recharge close to the outlet tends to generate much younger water than a uniform recharge. Velocity is higher for the shorter flow paths close to the discharge (Etcheverry, 2001; Leray et al., 2016). It is what is shown in Figure 4e for a constant thickness aquifer. While increasing the ratio $C_{R}$, the youngest waters are favoured and the RTD exhibits a power-law-like shape with a long tail to account for the large times induced by the low flows upstream (purple curve of Figure 4e). Inversely, increased recharge upstream tends to focus the distribution on older water and consequently drives the RTD to a unimodal distribution with residence times clustered around the MRT (black dash-dot curve of Figure 4e).

The aforementioned cases explore geometry and recharge rate effect independently. If both factors geometry and recharge rate - are variable, they can either compensate or accumulate and accordingly strongly impact the RTD. When the aquifer is diverging (Figure $4 \mathrm{~d}$ ), i.e. $C_{H} \gg 1$, increasing the ratio $C_{R}$ tends to reduce the effect of the divergence of flow by the increase of recharge downstream. Both factors compensate and result in an RTD close to the exponential model. When recharge and geometry follow exactly the same variation, i.e. $C_{H}=C_{R}$, they fully compensate 
and the classical exponential model is retrieved (black curve in Figures 4a-f). These conclusions extend previous works, including Haitjema's (1995), according to which the exponential model remains relevant as long as both the ratio $\tau=\frac{\theta H}{R}$ and the recharge $R$ remain constant. We show here that the recharge does not have to be constant to recover the exponential model as long as the ratio remains constant.

When the aquifer is diverging $-C_{H} \gg 1$ - and the recharge is decreasing downstream $-C_{R} \ll 1$, both trends increase the residence times by slowing down the flow downstream. In such a case, the RTD is typically controlled by the upstream oldest waters and becomes much narrower (black dash-dot curve of Figure 4d). In comparison to an aquifer of constant thickness with decreasing recharge downstream (black dash-dot curve of Figure 4e), the clustering of residence times close to the MRT is even more marked as both effects cumulate and the RTD becomes close to a Gamma distribution. Similarly-shaped RTD can be observed on Figure 4c. When the aquifer is converging (Figure 4f), i.e. $C_{H} \ll 1$, increasing the ratio $C_{R}$ further amplifies the increase of velocity close to the outlet. In that case, the RTD is typically controlled by the downstream and youngest waters. The RTD shifts towards lower residence times and has a strongly decreasing power-law-like shape with a long tail (black dash-dot curve of Figure $4 \mathrm{f}$ and Figure $4 \mathrm{a})$.

\subsection{Range and proportion of residence times}

Except in very specific cases where $C_{H}=C_{R}$, aquifer recharge and thickness provide a wide range of distribution shapes covering Gamma-like, uniform and truncated power-law shapes as well as any intermediary shapes. As a more quantitative assessment of the RTD variety, we have systematically computed a deviation criterion $D_{\sigma^{2}}$ to the exponential model, defined as:

$$
D_{\sigma^{2}}=\frac{\sigma^{2}}{\tau^{2}}
$$


where $\sigma^{2}$ is the variance of the RTD and $\tau^{2}$ is the expected variance in the exponential framework in which the variance is merely equal to the square of the MRT $\tau . D_{\sigma^{2}}$ is equal to one when the RTD is an exponential distribution. It is greater than 1 for wider RTDs, i.e. RTDs for which the standard deviation is larger than the MRT. Inversely, it is lower than 1 for narrower RTDs, i.e. RTDs for which the standard deviation is smaller than the MRT.

Figure 5 confirms the typology observed in the previous section. The RTD remains exponential on the diagonal line for $C_{H}=C_{R}$. Deviations occur in all other cases and can be significant. They are more pronounced for wider RTDs (upper left corner) than for narrower RTDs (lower right corner), the contour map having in proportion more greater values than lower values. Deviations to the expected variance in the exponential framework can reach almost 10 (upper left corner) corresponding to a ratio of variance to the squared MRT ten times higher than that of the exponential model. On the contrary, Gamma-like RTDs result in much narrower distributions up to one order of magnitude lower (lower right corner).

Looking at the first quartile of the RTDs leads to consistent conclusions. Figure 6 shows the deviation of the first quartile $D_{Q_{1}}$, defined as:

$$
D_{Q_{1}}=\frac{Q_{1}}{Q_{1}^{e x p}}
$$

where $Q_{1}$ is the first quartile of the RTD and $Q_{1}^{\exp }=\tau \ln \frac{1}{1-0.25}$ is the expected quartile in the exponential framework. Similar features as for $D_{\sigma^{2}}$ are observed. Except when $C_{H}=C_{R}$, the first quartile of the RTD significantly diverges from the exponential framework, leading up to almost a value of 3 for Gamma-like RTDs (lower right corner) and 0.03 for power-law-like RTDs. (upper right corner). The fraction of younger groundwater, is thus significantly higher or lower than given by the exponential framework. Taking the example of a converging aquifer with increasing recharge rate, the RTD is power-law-like with a long tail resulting in a wider RTD as mentioned above. In such conditions, disregarding system's complexity and applying the exponential model instead would lead 
to an under-representation of young waters and consequently in an overestimation of the first quartile of the RTD by an order of magnitude approximately. Most importantly, the quartile deviates quickly from the exponential model. This means that even a moderate variation of structure or recharge pattern may lead to substantial deviations. For instance, $C_{H}=2$ and $C_{R}=0.2$ leads to a deviation $D_{Q_{1}}$ close to 2 . Both deviations quantitatively confirm the significant impact of the aquifer shape and recharge distribution on the variance of the distribution as well as on its shape.

\section{Discussion}

\subsection{Practical interest of simple RTDs}

The analysis above shows that many mixing models can be obtained for aquifers with varying thicknesses under spatially evolving recharges. More precisely, the distribution results from a more complex weighting of the distance and velocity distributions complying with the flow continuity principle. As such, it can represent a wide variety of natural cases traducing the relative proportion of younger and older waters at the sampling location as well as the MRT as a function of the distribution of the volume within the aquifer following the equation 8. In this panel of RTD models, the exponential shape relevance is strictly limited to the very specific cases where the distribution of recharge distance from the sampling location is fully balanced by the distribution of velocity. More importantly, the standard deviation is not necessarily linked to the mean and the distribution cannot be fully defined by a unique parameter, requiring more than a single tracer to be measured.

The potentially large variations of RTD metrics, variance and first quartile of Figures 5 and 6 , show that additional information beyond the MRT are required to assess the fraction of younger or older waters represented for example by the first and last quartile of the distribution. Such information may be brought up by additional tracers or by a priori knowledge of the aquifer structure and recharge conditions, and, more generally, by the distribution of the recharge location and aquifer structure provided that the analytical developments presented in section 2 be consistently adapted. 
Without requiring to build a full aquifer model for flow and transport, the present Lumped Parameter Model can already account for various conditions and be used for management purposes as to evaluate the young water fraction, first quartile of the distribution. Such an evaluation may also be assessed in hydrogeological terms by the implicit representation of the flow line structure related to the shape of the RTD and illustrated in Figures 3 and 4. As a first approach, it might be used in a number of applications like the management of the groundwater quality, the restoration of hydrogeological systems or the assessment of the resource vulnerability.

\subsection{Domain of applicability}

Figure 7 shows the main characteristics of Figure 5 by superimposing aquifer types or morphologies. Without pretending to be exhaustive or specific to real sites, it presents some large aquifer classes thus forming a framework for the applicability of the semi-analytical solution. The latter possibly serving as a counterpart to advanced simulations of physically-distributed models that integrate more complexity - including for instance some heterogeneity. Few strongly divergent aquifers are represented in Figure 7. The reason for this is rather methodological given that the complete sampling of flowlines can hardly be achieved in such systems and consequently the present solution difficult to apply.

Regional alluvial basins such as the Paris (France) or Santiago (Chile) Basins are amongst the simplest systems in terms of structure (Cavelier and Pomerol, 1979; Iriarte et al., 2009; Millot et al., 2011). Such basins are also generally relatively thick, allowing to consider the saturated thickness of the upper, semi-confined or unconfined, aquifers as being relatively constant (Alluvial Basin of Figure 7). Natural recharge of such systems, if not close to major orogens, may be relatively uniform. Anthropized recharge conditions, on the other hand, can be more complex. Urbanization tends to waterproof surfaces, confine aquifers and thus localize recharge, e.g. the Upper Indus and Upper-Mid Ganges basins in the Indo-Gangetic basin alluvial aquifer (Bonsor et al., 2017). In rural contexts, agriculture modulates the recharge conditions according to irrigation and surface water 
management, e.g. the Walla Walla Basin in Oregon (Scherberg et al., 2018). At the catchment scale, delimited by local topographic highs, one can thus expect that in urban context, the recharge decreases towards the centre of the basin because of a greater proportion of impervious surface. To the opposite, in agricultural context, it might grow towards the centre of the basin due to a higher agricultural cover (Anthropized Alluvial Basin of Figure 7).

In mountainous context, orographic gradients are the first control of recharge. The increase in precipitation, together with the decrease in evapotranspiration, causes positive recharge gradients upstream of up to ten or more, e.g. the central Andes or the Rocky Mountains (Garreaud, 2009; Houston, 2009). If the mountainous block is sufficiently permeable, an aquifer with decreasing thickness downstream - following the geometry of the orogen - may eventually form (Mountain Block of Figure 7), e.g. the Salar de Atacama basin (Marazuela et al., 2019). On the other hand, if the mountainous block is not permeable enough, the effective precipitation is mainly converted into runoff. It can thus be diverted to the mountain front and in this case feed an alluvial basin located downstream (Piedmont with MFR of Figure 7). The Californian Central Basin aquifers (USGS, 2000) are a good example. The vast majority of the recharge comes from the mountain range upstream and the thickness of the basin increases downstream, e.g. the San Joaquin Valley.

In coastal context, the saltwater-freshwater interface determines the saturated thickness of the system which is decreasing and leads to a convergent flow towards the sea. If the aquifer is relatively local without a significant top-down topographic gradient, the recharge pattern remains relatively simple and uniform (Local or lowland coast of Figure 7). The Coastal Basin aquifers (California, (Barlow and Reichard, 2010; USGS, 2000)) may illustrate these conditions: they develop in intramountainous graben or depressions where the lateral mountains feed the aquifer with a continuous, more or less uniform, lateral recharge, converging to the Pacific Ocean. At regional scale, coastal ranges such as the Coast Cordillera in Chile or Sierra Nevada in Columbia (Houston, 2007; Lobo- 
Guerrero and Gilboa, 1987; Squeo et al., 2006) may include additional orographic effects increasing recharge upstream (Regional Coastal range of Figure 7).

At the more local hillslope scale, aquifer depth and saturated thickness may strongly evolve because of the weathering profile and dynamics (Rempe and Dietrich, 2014). With the additional convergence or divergence of the hillslopes towards the rivers (Troch et al., 2003), velocity generally evolves from uphill to downhill and conditions both the partition between the subsurface and surface flows and the transit times to the hydrographic network (Marçais et al., 2017). In crystalline basement especially where the unconfined aquifers remain relatively shallow within the weathered zone, the distribution of the residence time might thus be more controlled by the geomorphological structures of the catchment (Kolbe et al., 2016) and by major shifts in the permeability profile between soil and aquifer layers (Berghuijs and Kirchner, 2017) than by the vertical velocity profile. The depth reached by solutes may however be determinant for the degradation of other non-conservative solutes like nitrates, as the presence of reactive reduced elements may sharply increase with depth (Kolbe et al., 2018).

\section{Conclusions}

We have developed a semi-analytical approximation for trapezoidal aquifers exposed to linearlyvariable recharges. This new solution aims at complementing existing analytical RTDs and thereby further understanding the role and interaction of recharge conditions and aquifer structure. The solution has been developed for homogeneous 2D aquifer cross-sections in steady-state conditions following the Dupuit-Forchheimer assumption i.e. negligible vertical head gradient. Numerical simulations for 2D aquifers using Modflow and Modpath have been performed to validate the 1D approximation.

Validated against numerical simulations, the semi-analytical approximation proposed here presents all the distinguishing features of close-formed equations. It is formulated with a few parameters only, explicit and straightforward to use. It differentiates from existing solutions by its greater generality 
and flexibility. It can be used in a variety of aquifer configurations and recharge conditions. Accounting for aquifer structure and recharge gradients significantly modify the residence time distribution shape and properties. Apart from the very few cases where aquifer shape and recharge conditions have counterbalancing effects leading to classical exponential distributions, RTDs take a variety of non-trivial forms covering Gamma-like, truncated power-law-like and uniform distributions, amongst others.

Accounting for aquifer structures and recharge gradients appears critical to improve the prediction capacity in issues related to residence times including groundwater quality, vulnerability and management. It is as well pertinent for constraining RTDs from environmental tracer measurements, given their sensitivity to aquifer structure as identified in numerous studies. Further developments in this regard could imply a generalization of recharge and thickness conditions as well as the consideration of aquifer width variations. Numerical tools would allow in such conditions to cover in particular non-monotonic or parabolic variations and explore more complex aquifer structures. The impact of transient forcings on RTD could be as well more extendedly studied so as to quantify the relative effect of boundary conditions and hydrodynamic properties.

\section{Figures}

Figure 1: Sketch of the 2D trapezoidal aquifer of thickness $H(x)$ under linearly-evolving recharge rate $R(x)$. Under the assumption of Dupuit-Forchheimer, flow $F$ is a function of longitudinal position $x$ only and increases up to $F_{L}$ at the outlet $x=L$.

Figure 2: a) Normalized flow $F^{*}=\frac{F}{F_{L}}$ as a function of recharge location; b) Normalized residence time as a function of recharge position; c) Recharge position distribution as a function of recharge location; d) Derivative of the recharge position to residence time; e) Residence time distribution scaled by the mean residence time $\tau$ with the following simulation parameters: $C_{H}=\frac{2 \times 10^{2}}{10^{2}}=2[-], C_{R}=\frac{2 \times 10^{-3}}{10^{-2}}=0.2[-]$ and $\theta=10^{-2}[-]$ corresponding to the sketch of Figure 1.

Figure 3: Validation of the semi-analytical solution for Case $A: C_{H}=10$ and $C_{R}=0.1$. a) Analytical (red dash line) and numerical (blue filled line) residence time as a function of recharge position; b) Analytical (red dash line) and numerical (blue filled line) RTDs with mean residence time $\tau$ and standard deviation $\sigma ; c)$ Spatial evolution of transit time along flow lines in numerical simulations, including sketch to scale; d) Normalized horizontal velocity $v_{x}^{*}=\frac{v_{x} L}{\tau}$ and e) Normalized vertical velocity $v_{Z}^{*}=\frac{v_{Z} L}{\tau}$.

Figure 4: Normalized RTDs for various $C_{H}$ from $10^{-3}$ to $10^{3}$ when: a) $R$ significantly increases towards the discharge i.e. $\left.C_{R} \gg 1 ; b\right) R$ is uniform i.e. $C_{R}=1$; c) $R$ significantly decreases towards the discharge i.e. $C_{R} \ll 1$; and for various $C_{R}$ from $10^{-3}$ to $10^{3}$ when: d) $H$ significantly increases towards the discharge i.e. $C_{H} \gg 1$ (diverging aquifer); e) $H$ is constant i.e. $\left.C_{H}=1 ; f\right) H$ significantly decreases towards the discharge i.e. $C_{H} \ll 1$ (converging aquifer). When the RTD has an 
exponential shape, it is represented with black filled lines. Additional typical RTDs are represented with dash-dot lines: a) and f) truncated power-law-like; b) uniform; c) to e) Gamma-like.

Figure 5: Deviation of the variance of the semi-analytical RTDs in comparison to the exponential model, $D_{\sigma^{2}}$ as defined by equation 13, displayed within the $C_{H}$ and $C_{R}$ space interpolated from simulation results performed on a $20 \times 20$ parameter space regular gird. The full line $C_{H}=C_{R}$ leads to the exponential distribution and a value of 1 . Dash lines correspond to configurations where either recharge or thickness is kept constant (RTDs of Figure $4 b$ and Figure $4 e$ respectively). Four simple sketches of extreme configurations are further displayed at the corners where they apply.

Figure 6: Deviation of the first quartile of the semi-analytical RTDs in comparison to the exponential model, $D_{Q_{1}}$ as defined by equation 14. The additional features are the same as in Figure 5.

Figure 7: Domain of applicability of the semi-analytical solution exemplified with a few aquifer morphologies. The background is the same as in Figure 5.

\section{Appendices}

\section{A. Validation of the solution in confined conditions}

Figure A1: Validation of the semi-analytical solution. Case B: $C_{H}=0.1$ and $C_{R}=0.1$; Case $C: C_{H}=0.1$ and $C_{R}=10$; Case $D: C_{H}=10$ and $C_{R}=10$. The layout is the same as in Figure 3 .

\section{B. Validation of the solution for high aspect ratio}

Figure B. 1: Validity of the semi-analytical solution for an aspect ratio close to 1 . Case $E$ : $C_{H}=10$ and $C_{R}=0.1$; Case F: $C_{H}=10$ and $C_{R}=10$. The layout is the same as in Figure 3.

\section{Validation of the solution in unconfined conditions}

Figure C. 1: Validity of the semi-analytical solution for unconfined aquifers. Case $G: C_{H}=0.75$ and $C_{R}=1 ;$ Case $H$ : $C_{H}=0.5$ and $C_{R}=1$ and Case l: $C_{H}=0.1$ and $C_{R}=1$. The layout is the same as in Figure 3 .

\section{Acknowledgments}

Sarah Leray acknowledges funding from the project CONICYT/Fondecyt de Iniciación 11170380.

\section{References}

Amin, I.E., Campana, M.E., 1996. A general lumped parameter model for the interpretation of tracer data and transit time calculation in hydrologic systems. Journal of Hydrology 179, 1-21. https://doi.org/10.1016/0022-1694(95)02880-3 
Barlow, P.M., Reichard, E.G., 2010. Saltwater intrusion in coastal regions of North America. Hydrogeol J 18, 247-260. https://doi.org/10.1007/s10040-009-0514-3

Basu, N.B., Jindal, P., Schilling, K.E., Wolter, C.F., Takle, E.S., 2012. Evaluation of analytical and numerical approaches for the estimation of groundwater travel time distribution. Journal of Hydrology 475, 65-73. https://doi.org/10.1016/j.jhydrol.2012.08.052

Berghuijs, W.R., Kirchner, J.W., 2017. The relationship between contrasting ages of groundwater and streamflow. Geophysical Research Letters 44, 8925-8935. https://doi.org/10.1002/2017GL074962

Bethke, C.M., Johnson, T.M., 2002. Paradox of groundwater age. Geology 30, 107-110. https://doi.org/10.1130/0091-7613(2002)030<0107:POGA>2.0.CO;2

Bonsor, H.C., MacDonald, A.M., Ahmed, K.M., Burgess, W.G., Basharat, M., Calow, R.C., Dixit, A., Foster, S.S.D., Gopal, K., Lapworth, D.J., Moench, M., Mukherjee, A., Rao, M.S., Shamsudduha, M., Smith, L., Taylor, R.G., Tucker, J., van Steenbergen, F., Yadav, S.K., Zahid, A., 2017. Hydrogeological typologies of the Indo-Gangetic basin alluvial aquifer, South Asia. Hydrogeol J 25, 1377-1406. https://doi.org/10.1007/s10040-017-1550-z

Botter, G., Bertuzzo, E., Rinaldo, A., 2010. Transport in the hydrologic response: Travel time distributions, soil moisture dynamics, and the old water paradox. Water Resources Research 46. https://doi.org/10.1029/2009WR008371

Bresciani, E., Gleeson, T., Goderniaux, P., de Dreuzy, J.R., Werner, A.D., Wörman, A., Zijl, W., Batelaan, O., 2016a. Groundwater flow systems theory: research challenges beyond the specified-head top boundary condition. Hydrogeol J 24, 1087-1090. https://doi.org/10.1007/s10040-016-1397-8

Bresciani, E., Goderniaux, P., Batelaan, O., 2016b. Hydrogeological controls of water table-land surface interactions. Geophysical Research Letters 43, 9653-9661. https://doi.org/10.1002/2016GL070618

Campana, M.E., 1987. Generation of Ground-Water Age Distributions. Groundwater 25, 51-58. https://doi.org/10.1111/j.1745-6584.1987.tb02115.x

Cardenas, M.B., 2007. Potential contribution of topography-driven regional groundwater flow to fractal stream chemistry: Residence time distribution analysis of Tóth flow. Geophysical Research Letters 34. https://doi.org/10.1029/2006GL029126

Cavelier, C., Pomerol, C., 1979. Chronologie et interprétation des évènements tectoniques cénozoïques dans le Bassin de Paris. Bulletin de la Société Géologique de France 7, 33-48.

Chesnaux, R., Molson, J.W., Chapuis, R.P., 2005. An analytical solution for ground water transit time through unconfined aquifers. Ground Water 43, 511-517. https://doi.org/10.1111/j.17456584.2005.0056.x

Cirpka, O.A., Kitanidis, P.K., 2001. Travel-Time Based Model of Bioremediation Using Circulation Wells. Groundwater 39, 422-432. https://doi.org/10.1111/j.1745-6584.2001.tb02326.x

Condon, L.E., Maxwell, R.M., 2015. Evaluating the relationship between topography and groundwater using outputs from a continental-scale integrated hydrology model. Water Resources Research 51, 6602-6621. https://doi.org/10.1002/2014WR016774

Cook, P.G., Böhlke, J.-K., 2000. Determining Timescales for Groundwater Flow and Solute Transport, in: Cook, P.G., Herczeg, A.L. (Eds.), Environmental Tracers in Subsurface Hydrology. Springer US, Boston, MA, pp. 1-30. https://doi.org/10.1007/978-1-4615-4557-6_1

Cook, P.G., Herczeg, A.L., 2000. Environmental Tracers in Subsurface Hydrology. Springer. 
Danckwerts, P.V., 1953. Continuous flow systems: Distribution of residence times. Chemical Engineering Science 2, 1-13. https://doi.org/10.1016/0009-2509(53)80001-1

Dupuit, J., 1863. Etudes Théoriques et Pratiques sur le mouvement des Eaux dans les canaux découverts et à travers les terrains perméables, Second Ed. ed. Dunod, Paris.

Eberts, S.M., Böhlke, J.K., Kauffman, L.J., Jurgens, B.C., 2012. Comparison of particle-tracking and lumped-parameter age-distribution models for evaluating vulnerability of production wells to contamination. Hydrogeol J 20, 263-282. https://doi.org/10.1007/s10040-011-0810-6

Engdahl, N.B., 2017. Transient effects on confined groundwater age distributions: Considering the necessity of time-dependent simulations. Water Resources Research 53, 7332-7348. https://doi.org/10.1002/2016WR019916

Engdahl, N.B., Maxwell, R.M., 2015. Quantifying changes in age distributions and the hydrologic balance of a high-mountain watershed from climate induced variations in recharge. Journal of Hydrology 522, 152-162. https://doi.org/10.1016/j.jhydrol.2014.12.032

Eriksson, E., 1958. The Possible Use of Tritium' for Estimating Groundwater Storage. Tellus 10, $472-$ 478. https://doi.org/10.1111/j.2153-3490.1958.tb02035.x

Etcheverry, D., 2001. Une approche déterministe des distributions des temps de transit de l'eau souterraine par la théorie des réservoirs. Neuchâtel, Neuchâtel.

Forchheimer, P., 1886. Über die Ergiebigkeit von Brunnen-Anlagen und Sickerschlitzen. Z. Architekt. Ing.-Ver. 32, 539-563.

Garreaud, R.D., 2009. The Andes climate and weather, in: Advances in Geosciences. Presented at the 4th EGU Alexander von Humboldt Conference "The Andes: Challenge for Geosciences" - 4th Alexander von Humboldt International Conference on The Andes: Challenge for Geosciences, Santiago de Chile, Chile, 24\&ndash;28 November 2008, Copernicus GmbH, pp. 3-11. https://doi.org/10.5194/adgeo-22-3-2009

Ginn, T.R., Haeri, H., Massoudieh, A., Foglia, L., 2009. Notes on Groundwater Age in Forward and Inverse Modeling. Transp Porous Med 79, 117-134. https://doi.org/10.1007/s11242-0099406-1

Gleeson, T., Marklund, L., Smith, L., Manning, A.H., 2011. Classifying the water table at regional to continental scales. Geophysical Research Letters 38. https://doi.org/10.1029/2010GL046427

Goderniaux, P., Davy, P., Bresciani, E., de Dreuzy, J.-R., Le Borgne, T., 2013. Partitioning a regional groundwater flow system into shallow local and deep regional flow compartments: GROUNDWATER PARTITIONING. Water Resources Research 49, 2274-2286. https://doi.org/10.1002/wrcr.20186

Haitjema, H., 2006. The Role of Hand Calculations in Ground Water Flow Modeling. Groundwater 44, 786-791. https://doi.org/10.1111/j.1745-6584.2006.00189.x

Haitjema, H.M., 1995. On the residence time distribution in idealized groundwatersheds. Journal of Hydrology 172, 127-146. https://doi.org/10.1016/0022-1694(95)02732-5

Haitjema, H.M., 1987. Comparing a three-dimensional and a Dupuit-Forchheimer solution for a circular recharge area in a confined aquifer. Journal of Hydrology 91, 83-101. https://doi.org/10.1016/0022-1694(87)90130-2

Haitjema, H.M., Mitchell-Bruker, S., 2005. Are Water Tables a Subdued Replica of the Topography? Groundwater 43, 781-786. https://doi.org/10.1111/j.1745-6584.2005.00090.x 
Harbaugh, A.W., Langevin, C.D., Hughes, J.D., Niswonger, R.G., Konikow, L.F., 2017. MODFLOW-2005: USGS three-dimensional finite-difference groundwater model. https://doi.org/10.5066/F7RF5S7G

Houston, J., 2009. A recharge model for high altitude, arid, Andean aquifers. Hydrological Processes 23, 2383-2393. https://doi.org/10.1002/hyp.7350

Houston, J., 2007. Recharge to groundwater in the Turi Basin, northern Chile: An evaluation based on tritium and chloride mass balance techniques. Journal of Hydrology 334, 534-544. https://doi.org/10.1016/j.jhydrol.2006.10.030

IAEA, 2006. Use of Chlorofluorocarbons in Hydrology.

Iriarte, S., Atenas, M., Aguirre, E., Tore, C., 2009. Aquifer recharge and contamination determination using environmental isotopes: Santiago basin, Chile: A study case. Presented at the Studies of isotopic hydrology in Latin America 2006, International Atomic Energy Agency, Isotope Hydrology Section, Vienna (Austria), pp. 97-112.

Ivey, S., Gentry, R.W., Anderson, J., 2008. Inverse Application of Age-Distribution Modeling Using Environmental Tracers H3 / He3. Journal of Hydrologic Engineering 13, 1002-1010. https://doi.org/10.1061/(ASCE)1084-0699(2008)13:11(1002)

Jing, M., Heße, F., Kumar, R., Kolditz, O., Kalbacher, T., Attinger, S., 2019. Influence of input and parameter uncertainty on the prediction of catchment-scale groundwater travel time distributions. Hydrology and Earth System Sciences 23, 171-190. https://doi.org/10.5194/hess-23-171-2019

Jones, E., Oliphant, E., Peterson, P., others, 2001. SciPy: Open Source Scientific Tools for Python [WWW Document]. URL http://www.scipy.org/ (accessed 12.31.18).

Jurgens, B.C., Böhlke, J., Eberts, S.M., 2012. TracerLPM (Version 1): An Excel ${ }^{\circledR}$ workbook for interpreting groundwater age distributions from environmental tracer data (No. 2328-7055). US Geological Survey.

Jurgens, B.C., Böhlke, J.K., Kauffman, L.J., Belitz, K., Esser, B.K., 2016. A partial exponential lumped parameter model to evaluate groundwater age distributions and nitrate trends in longscreened wells. Journal of Hydrology, RESIDENCE TIMES IN SUBSURFACE HYDROLOGICAL SYSTEMS: Signature of hydrological processes and impact on environmental applications 543, 109-126. https://doi.org/10.1016/j.jhydrol.2016.05.011

Kazemi, G.A., Lehr, J.H., Perrochet, P., 2005. Groundwater Age, John Wiley \& Sons, Inc. ed.

Kirchner, J.W., 2016. Aggregation in environmental systems - Part 1: Seasonal tracer cycles quantify young water fractions, but not mean transit times, in spatially heterogeneous catchments. Hydrology and Earth System Sciences 20, 279-297. https://doi.org/10.5194/hess-20-2792016

Kirchner, J.W., Feng, X., Neal, C., 2001. Catchment-scale advection and dispersion as a mechanism for fractal scaling in stream tracer concentrations. Journal of Hydrology 254, 82-101. https://doi.org/10.1016/S0022-1694(01)00487-5

Knowles, L., Katz, B.G., Toth, D.J., 2010. Using multiple chemical indicators to characterize and determine the age of groundwater from selected vents of the Silver Springs Group, central Florida, USA. Hydrogeol J 18, 1825-1838. https://doi.org/10.1007/s10040-010-0669-y

Koh, D.-C., Niel Plummer, L., Kip Solomon, D., Busenberg, E., Kim, Y.-J., Chang, H.-W., 2006. Application of environmental tracers to mixing, evolution, and nitrate contamination of ground water in Jeju Island, Korea. Journal of Hydrology 327, 258-275. https://doi.org/10.1016/j.jhydrol.2005.11.021 
Koh, E.-H., Lee, E., Kaown, D., Green, C.T., Koh, D.-C., Lee, K.-K., Lee, S.H., 2018. Comparison of groundwater age models for assessing nitrate loading, transport pathways, and management options in a complex aquifer system. Hydrological Processes 32, 923-938. https://doi.org/10.1002/hyp.11465

Kolbe, T., De Dreuzy, J.-R., Abbott, B.W., Marçais, J., Babey, T., Laverman, T., Labasque, T., Aquilina, L., Thomas, Z., Pinay, G., 2018. Structure of groundwater denitrification. Proceedings of the National Academy of Sciences. https://doi.org/In press

Kolbe, T., Marçais, J., Thomas, Z., Abbott, B.W., de Dreuzy, J.-R., Rousseau-Gueutin, P., Aquilina, L., Labasque, T., Pinay, G., 2016. Coupling 3D groundwater modeling with CFC-based age dating to classify local groundwater circulation in an unconfined crystalline aquifer. Journal of Hydrology, RESIDENCE TIMES IN SUBSURFACE HYDROLOGICAL SYSTEMS: Signature of hydrological processes and impact on environmental applications 543, 31-46. https://doi.org/10.1016/j.jhydrol.2016.05.020

Leray, S., de Dreuzy, J.-R., Bour, O., Labasque, T., Aquilina, L., 2012. Contribution of age data to the characterization of complex aquifers. Journal of Hydrology 464-465, 54-68. https://doi.org/10.1016/j.jhydrol.2012.06.052

Leray, S., Engdahl, N.B., Massoudieh, A., Bresciani, E., McCallum, J., 2016. Residence time distributions for hydrologic systems: Mechanistic foundations and steady-state analytical solutions. Journal of Hydrology, RESIDENCE TIMES IN SUBSURFACE HYDROLOGICAL SYSTEMS: Signature of hydrological processes and impact on environmental applications 543, 67-87. https://doi.org/10.1016/j.jhydrol.2016.01.068

Lobo-Guerrero, A., Gilboa, Y., 1987. Groundwater in Colombia. Hydrological Sciences Journal 32, 161-178. https://doi.org/10.1080/02626668709491175

Long, A.J., Putnam, L.D., 2006. Translating CFC-based piston ages into probability density functions of ground-water age in karst. Journal of Hydrology 330, 735-747. https://doi.org/10.1016/j.jhydrol.2006.05.004

Luo, J., Kitanidis, P.K., 2004. Fluid residence times within a recirculation zone created by an extraction-injection well pair. Journal of Hydrology 295, 149-162. https://doi.org/10.1016/j.jhydrol.2004.03.006

Małoszewski, P., Zuber, A., 1982. Determining the turnover time of groundwater systems with the aid of environmental tracers: 1 . Models and their applicability. Journal of Hydrology 57, 207231. https://doi.org/10.1016/0022-1694(82)90147-0

Manning, A.H., Caine, J.S., 2007. Groundwater noble gas, age, and temperature signatures in an Alpine watershed: Valuable tools in conceptual model development. Water Resources Research 43. https://doi.org/10.1029/2006WR005349

Marazuela, M.A., Vázquez-Suñé, E., Ayora, C., García-Gil, A., Palma, T., 2019. Hydrodynamics of salt flat basins: The Salar de Atacama example. Science of The Total Environment 651, 668-683. https://doi.org/10.1016/j.scitotenv.2018.09.190

Marçais, J., de Dreuzy, J.-R., Erhel, J., 2017. Dynamic coupling of subsurface and seepage flows solved within a regularized partition formulation. Advances in Water Resources 109, 94-105. https://doi.org/10.1016/j.advwatres.2017.09.008

MATLAB and Statistics Toolbox, 2012. . The MathWorks, Inc., Natick, Massachusetts, United States.

Maxwell, R.M., Condon, L.E., Kollet, S.J., Maher, K., Haggerty, R., Forrester, M.M., 2016. The imprint of climate and geology on the residence times of groundwater. Geophysical Research Letters 43, 701-708. https://doi.org/10.1002/2015GL066916 
McGuire, K.J., McDonnell, J.J., 2006. A review and evaluation of catchment transit time modeling. Journal of Hydrology 330, 543-563. https://doi.org/10.1016/j.jhydrol.2006.04.020

Millman, K.J., Aivazis, M., 2011. Python for Scientists and Engineers. Computing in Science Engineering 13, 9-12. https://doi.org/10.1109/MCSE.2011.36

Millot, R., Guerrot, C., Innocent, C., Négrel, P., Sanjuan, B., 2011. Chemical, multi-isotopic (Li-B-Sr$\mathrm{U}-\mathrm{H}-\mathrm{O})$ and thermal characterization of Triassic formation waters from the Paris Basin. Chemical Geology 283, 226-241. https://doi.org/10.1016/j.chemgeo.2011.01.020

Niu, Y., Castro, M.C., Hall, C.M., Aciego, S.M., Arendt, C.A., 2017. Characterizing glacial meltwater sources in the Athabasca Glacier, Canada, using noble gases as tracers. Applied Geochemistry 76, 136-147. https://doi.org/10.1016/j.apgeochem.2016.11.015

Oliphant, T.E., 2007. Python for Scientific Computing. Computing in Science \& Engineering 9, 10-20. https://doi.org/10.1109/MCSE.2007.58

Osenbrück, K., Fiedler, S., Knöller, K., Weise, S.M., Sültenfuß, J., Oster, H., Strauch, G., 2006. Timescales and development of groundwater pollution by nitrate in drinking water wells of the Jahna-Aue, Saxonia, Germany. Water Resources Research 42. https://doi.org/10.1029/2006WR004977

Pinay, G., Peiffer, S., De Dreuzy, J.-R., Krause, S., Hannah, D.M., Fleckenstein, J.H., Sebilo, M., Bishop, K., Hubert-Moy, L., 2015. Upscaling Nitrogen Removal Capacity from Local Hotspots to Low Stream Orders' Drainage Basins. Ecosystems 18, 1101-1120. https://doi.org/10.1007/s10021-015-9878-5

Pollock, D.W., 2016. MODPATH: A particle-tracking model for MODFLOW. https://doi.org/10.5066/F70P0X5X

Raats, P.A.C., 1977. Convective transport of solutes by steady flows II. Specific flow problems. Agricultural Water Management 1, 219-232. https://doi.org/10.1016/0378-3774(77)90002-6

Rempe, D.M., Dietrich, W.E., 2014. A bottom-up control on fresh-bedrock topography under landscapes. PNAS 111, 6576-6581. https://doi.org/10.1073/pnas.1404763111

Scherberg, J., Keller, J., Patten, S., Baker, T., Milczarek, M., 2018. Modeling the impact of aquifer recharge, in-stream water savings, and canal lining on water resources in the Walla Walla Basin. Sustain. Water Resour. Manag. 4, 275-289. https://doi.org/10.1007/s40899-018-0215y

Solomon, D.K., Genereux, D.P., Plummer, L.N., Busenberg, E., 2010. Testing mixing models of old and young groundwater in a tropical lowland rain forest with environmental tracers. Water Resources Research 46. https://doi.org/10.1029/2009WR008341

Squeo, F.A., Aravena, R., Aguirre, E., Pollastri, A., Jorquera, C.B., Ehleringer, J.R., 2006. Groundwater dynamics in a coastal aquifer in north-central Chile: Implications for groundwater recharge in an arid ecosystem. Journal of Arid Environments 67, 240-254. https://doi.org/10.1016/j.jaridenv.2006.02.012

Tóth, J., 1963. A theoretical analysis of groundwater flow in small drainage basins. Journal of Geophysical Research 68, 4795-4812. https://doi.org/10.1029/JZ068i016p04795

Troch, P.A., Paniconi, C., Loon, E.E. van, 2003. Hillslope-storage Boussinesq model for subsurface flow and variable source areas along complex hillslopes: 1 . Formulation and characteristic response. Water Resources Research 39. https://doi.org/10.1029/2002WR001728

Turnadge, C., Smerdon, B.D., 2014. A review of methods for modelling environmental tracers in groundwater: Advantages of tracer concentration simulation. Journal of Hydrology 519, 3674-3689. https://doi.org/10.1016/j.jhydrol.2014.10.056 
USGS, 2000. Ground water atlas of the United States. James A. Miller, Reston, Virginia.

Velde, Y. van der, Torfs, P.J.J.F., Zee, S.E.A.T.M. van der, Uijlenhoet, R., 2012. Quantifying catchmentscale mixing and its effect on time-varying travel time distributions. Water Resources Research 48. https://doi.org/10.1029/2011WR011310

Visser, A., Broers, H.P., Purtschert, R., Sültenfuß, J., Jonge, M. de, 2013. Groundwater age distributions at a public drinking water supply well field derived from multiple age tracers $(85 \mathrm{Kr}, 3 \mathrm{H} / 3 \mathrm{He}$, and 39Ar). Water Resources Research 49, 7778-7796. https://doi.org/10.1002/2013WR014012

Vogel, J.C., 1967. Investigation of groundwater flow with radiocarbon. Presented at the Symposium on isotopes in hydrology, International Atomic Energy Agency, Vienna (Austria), pp. 355-369.

Wang, J.-Z., Wörman, A., Bresciani, E., Wan, L., Wang, X.-S., Jiang, X.-W., 2016. On the use of latetime peaks of residence time distributions for the characterization of hierarchically nested groundwater flow systems. Journal of Hydrology, RESIDENCE TIMES IN SUBSURFACE HYDROLOGICAL SYSTEMS: Signature of hydrological processes and impact on environmental applications 543, 47-58. https://doi.org/10.1016/j.jhydrol.2016.04.034

Warrier, R.B., Castro, M.C., Hall, C.M., 2012. Recharge and source-water insights from the Galapagos Islands using noble gases and stable isotopes. Water Resources Research 48. https://doi.org/10.1029/2011WR010954

Welch, L.A.A., Allen, D.M.M., Meerveld, H.J. (Ilja) van, 2012. Topographic Controls on Deep Groundwater Contributions to Mountain Headwater Streams and Sensitivity to Available Recharge. Canadian Water Resources Journal / Revue canadienne des ressources hydriques 37, 349-371. https://doi.org/10.4296/cwrj2011-907 
Residence Time Distributions in non-uniform aquifer recharge and thickness conditions

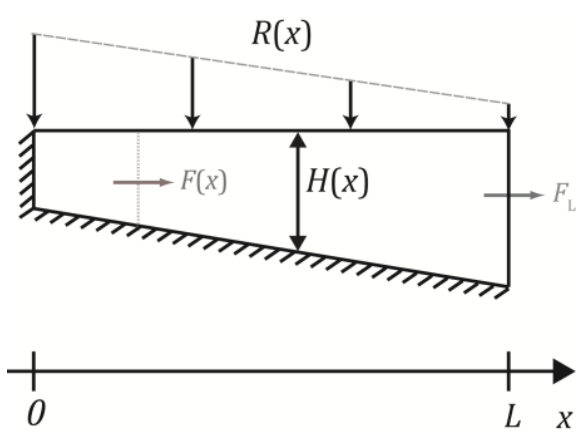


Residence Time Distributions in non-uniform aquifer recharge and thickness conditions
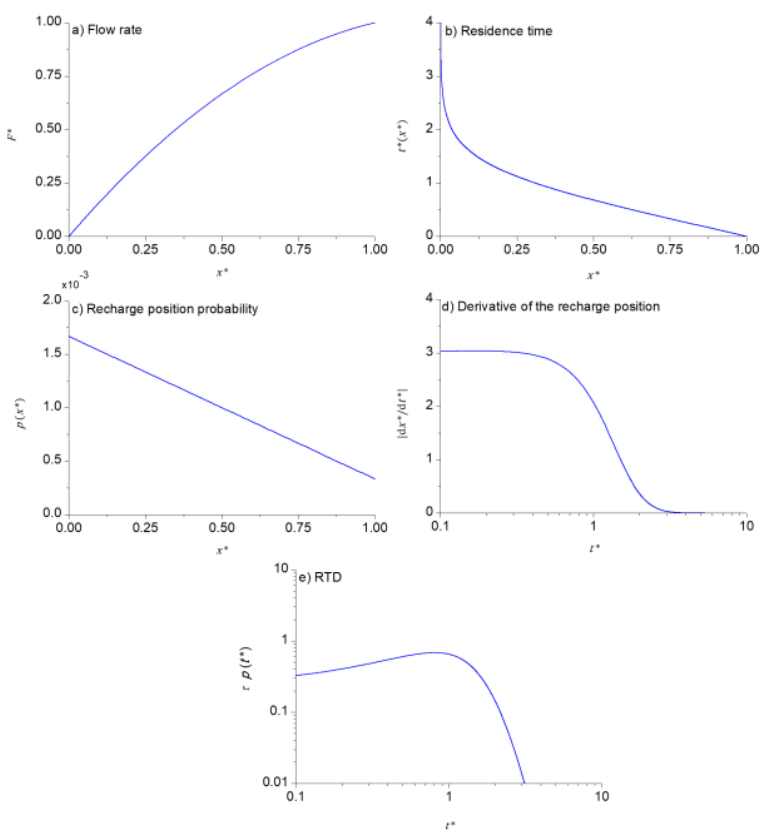
Case A: $C_{H}=10$ and $C_{R}=0.1$

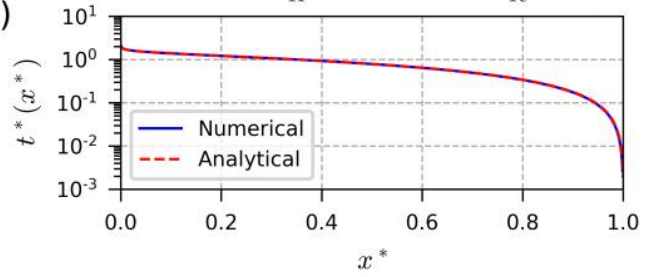

b)
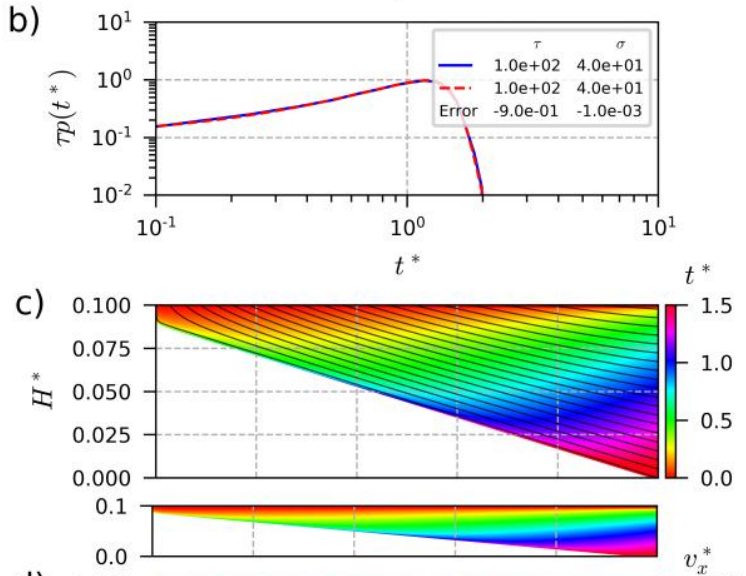

d) 0.100
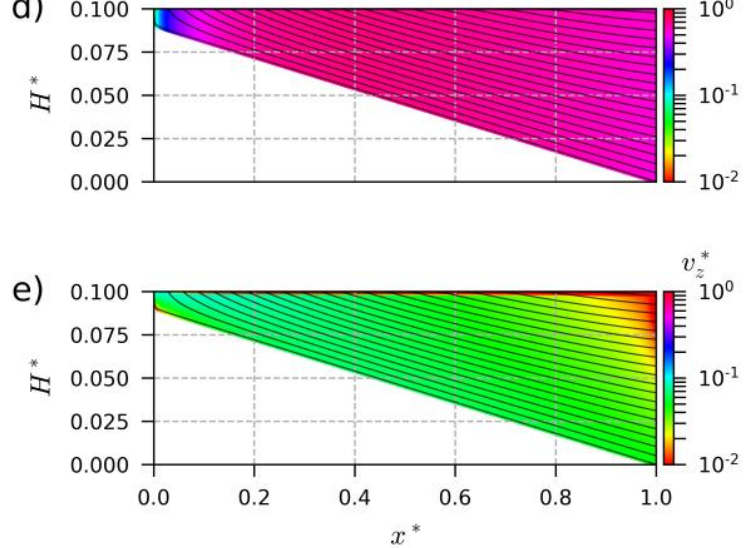
Residence Time Distributions in non-uniform aquifer recharge and thickness conditions
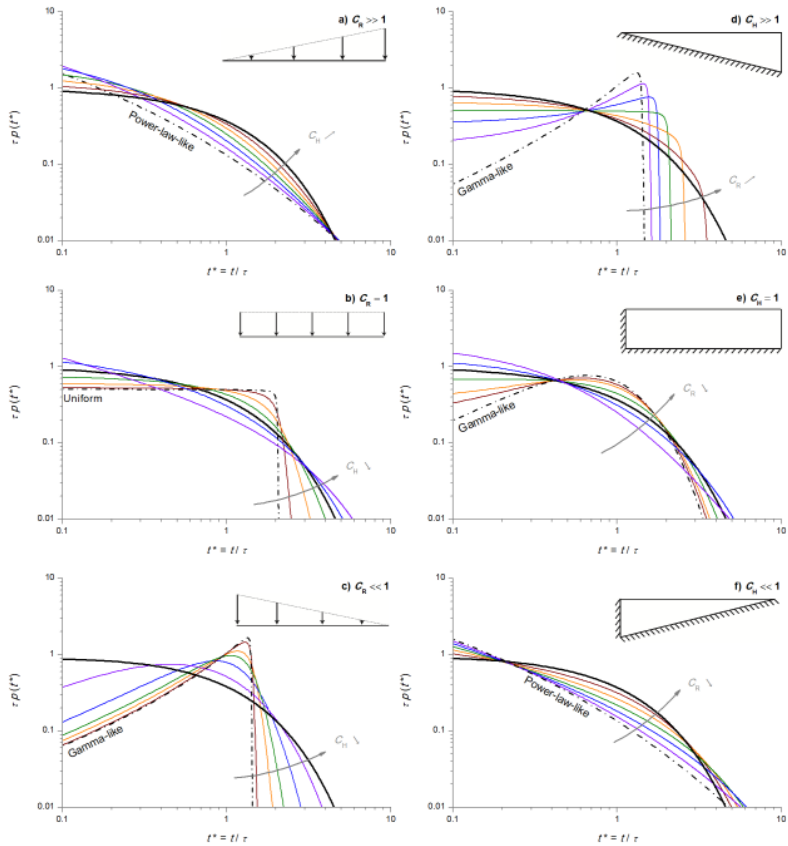


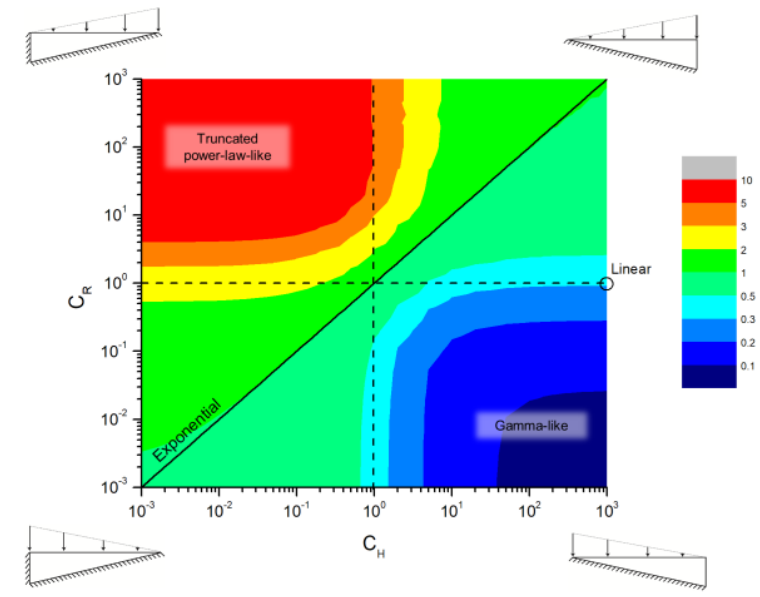




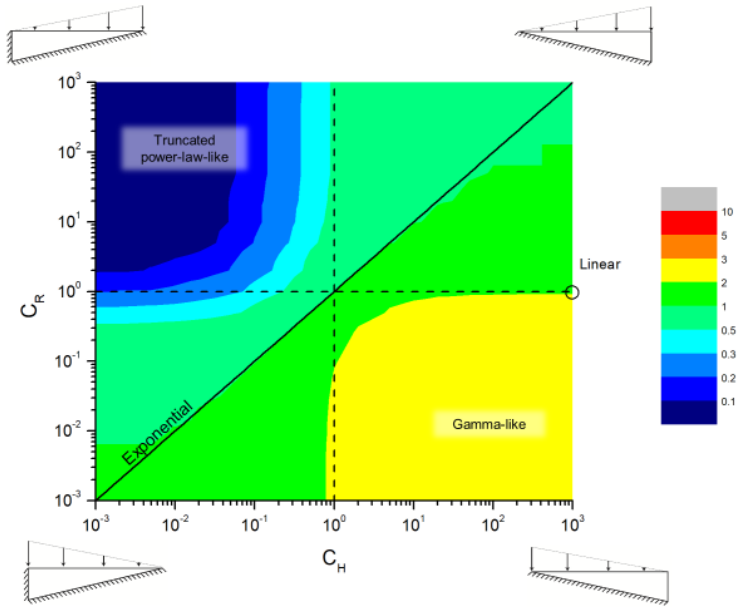


Residence Time Distributions in non-uniform aquifer recharge and thickness conditions

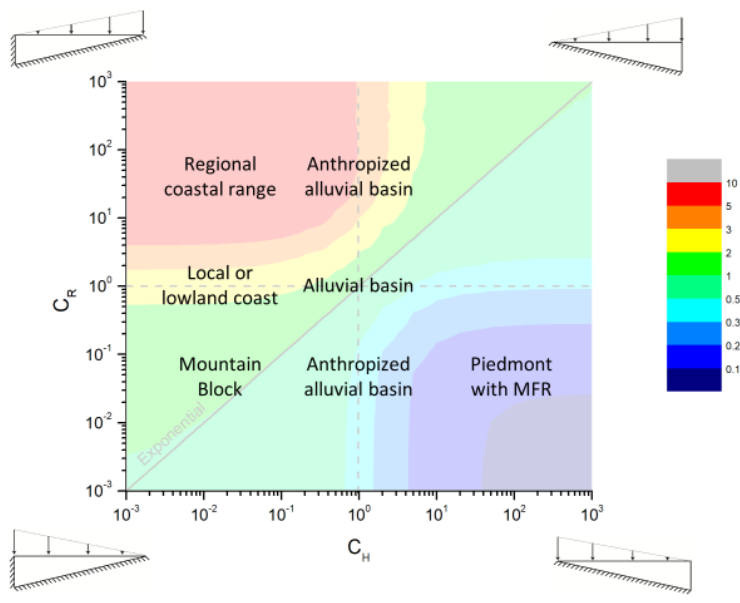


Case B: $C_{H}=0.1$ and $C_{R}=0.1$

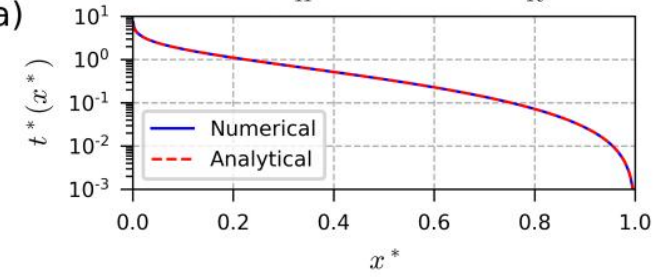

b)
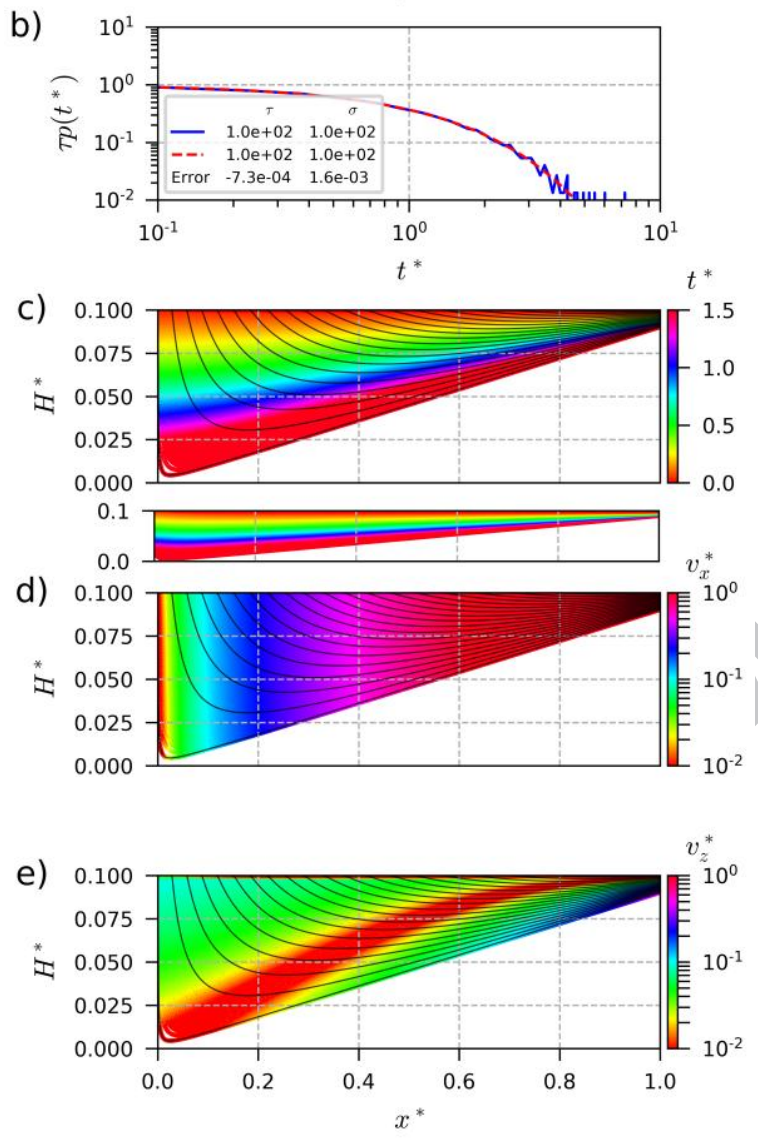
Case C: $C_{H}=0.1$ and $C_{R}=10$
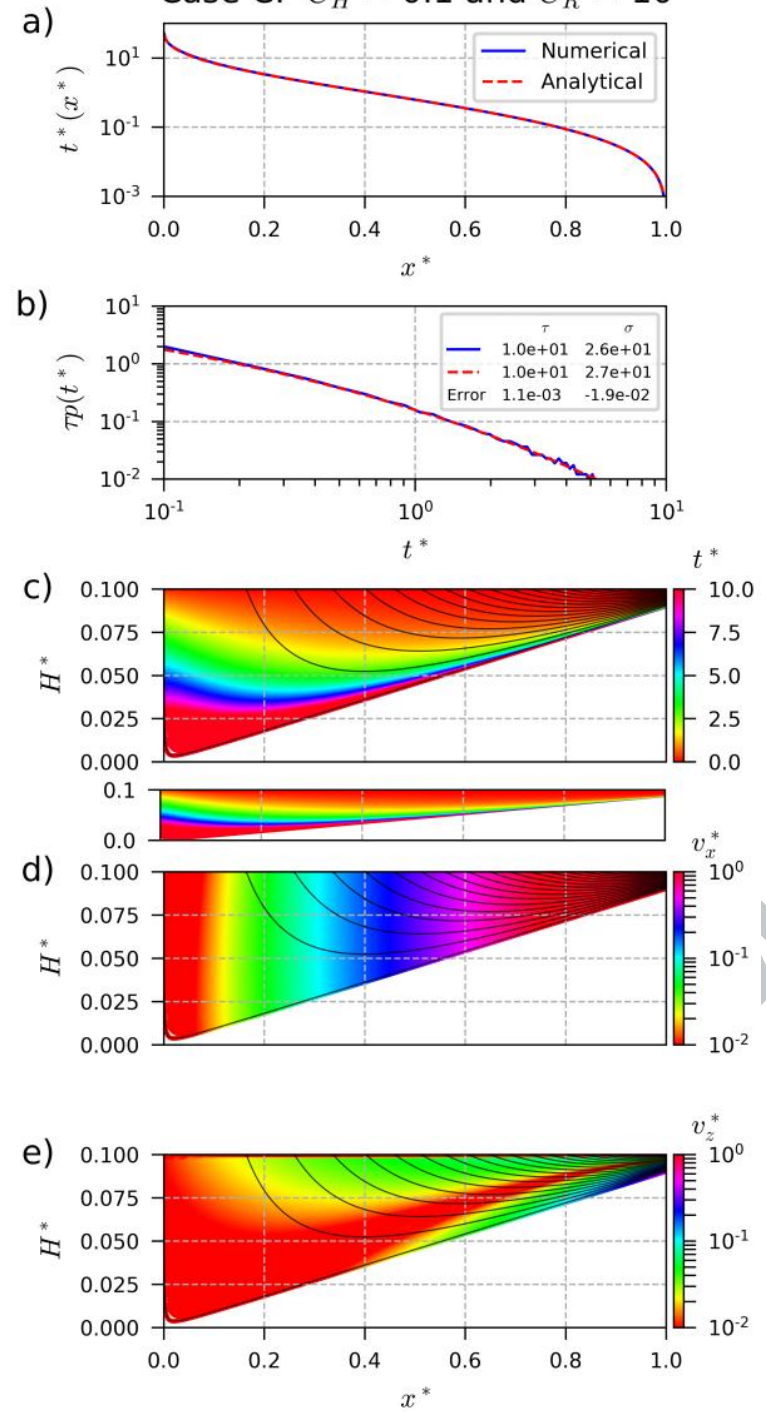
Case D: $C_{H}=10$ and $C_{R}=10$

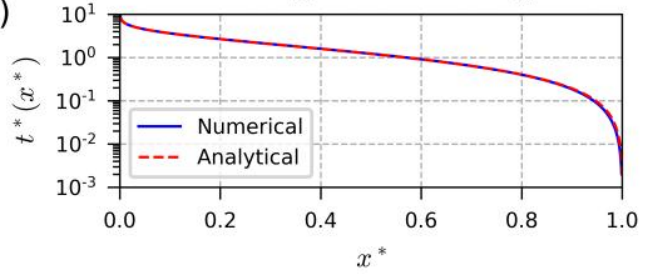

b)
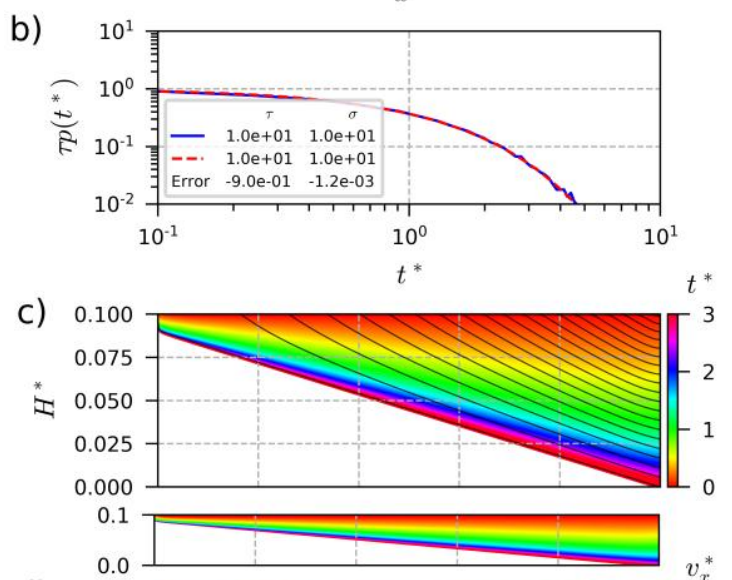

d)
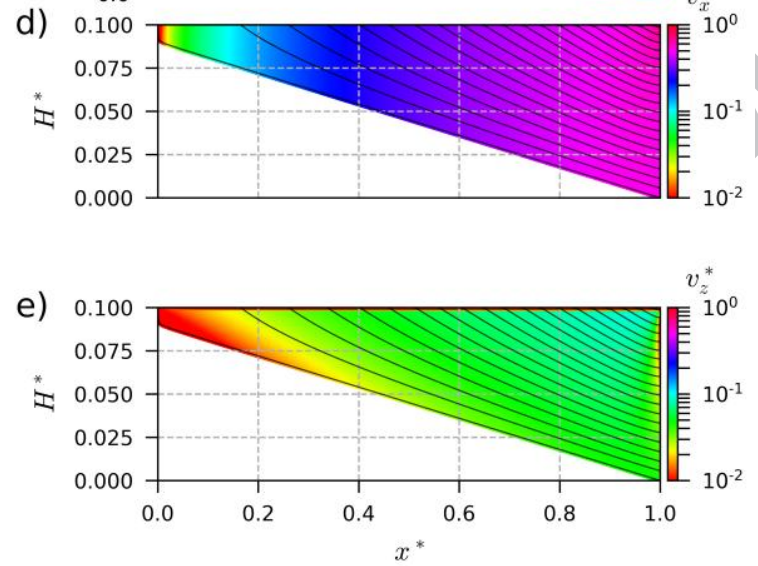
Case E: $C_{H}=10$ and $C_{R}=0.1$

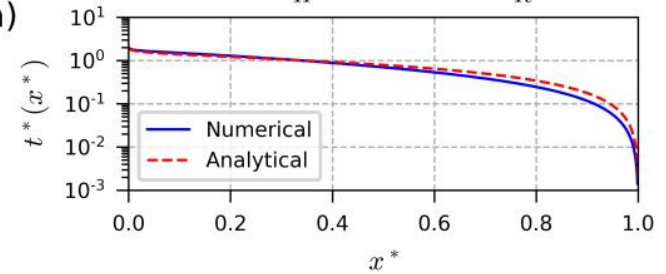

b)

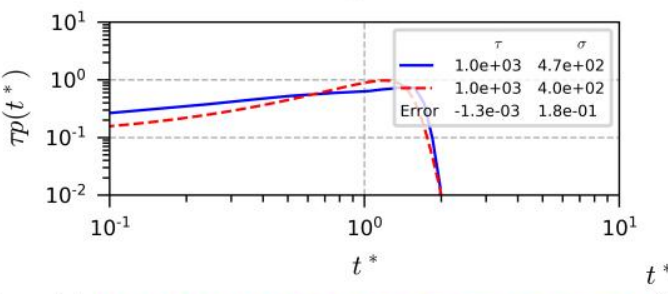

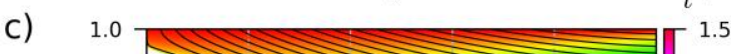

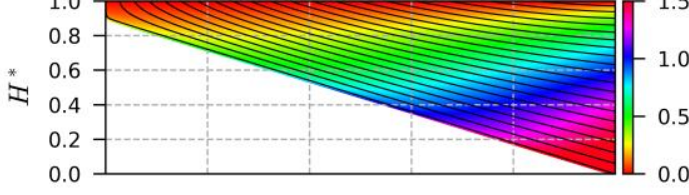

d)

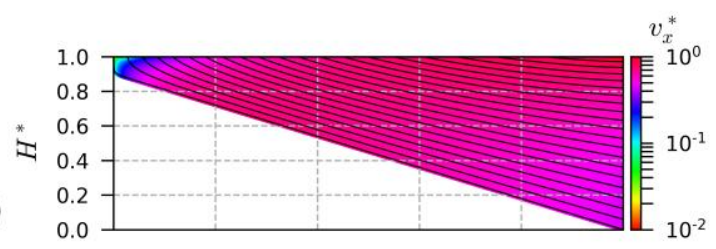

e)

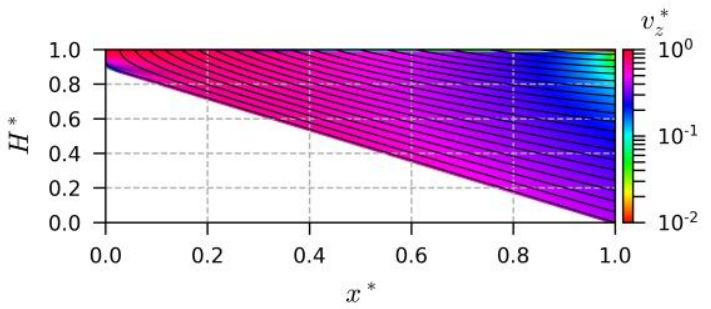


a) Case F: $C_{H}=10$ and $C_{R}=10$

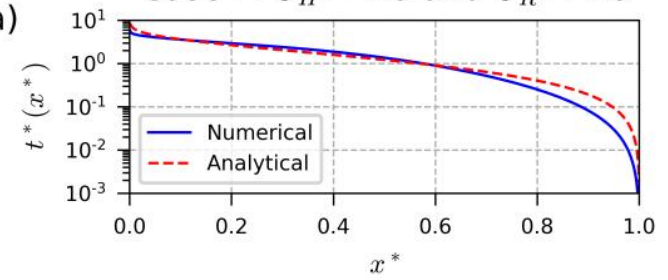

b)

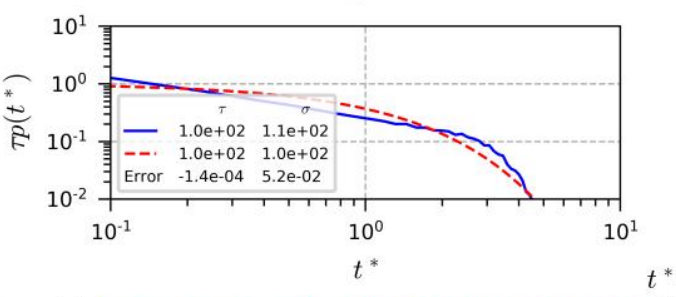

c)

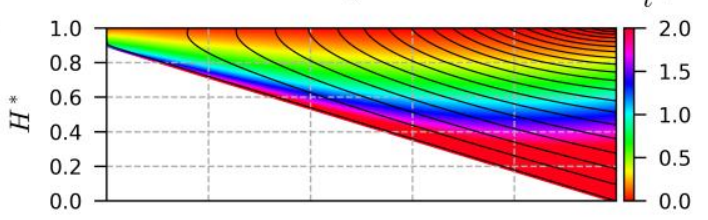

d)

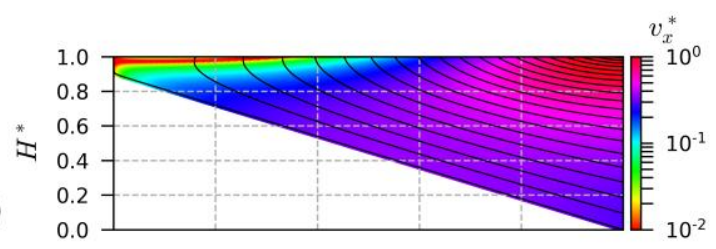

e)

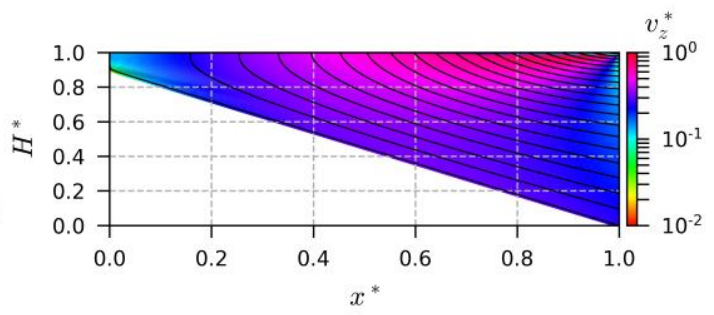


Case G: $C_{H}=0.75$ and $C_{R}=1$

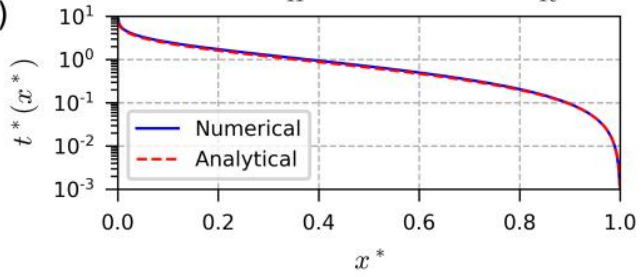

b)
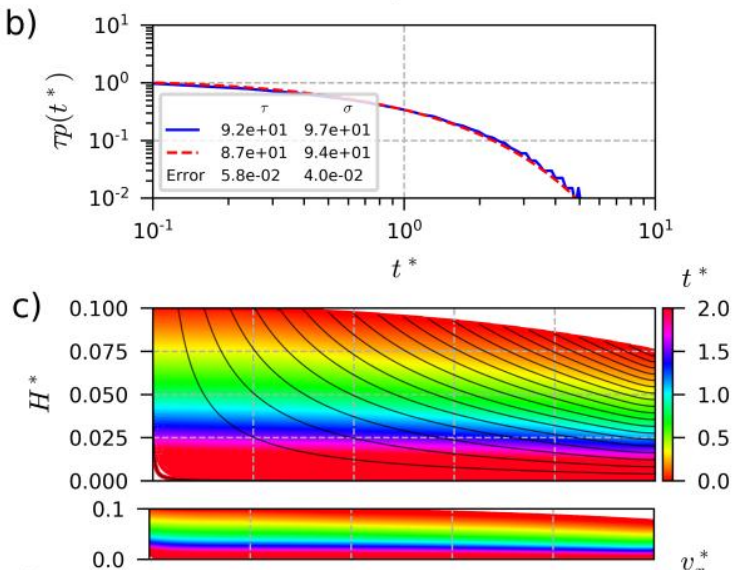

d) 0.100
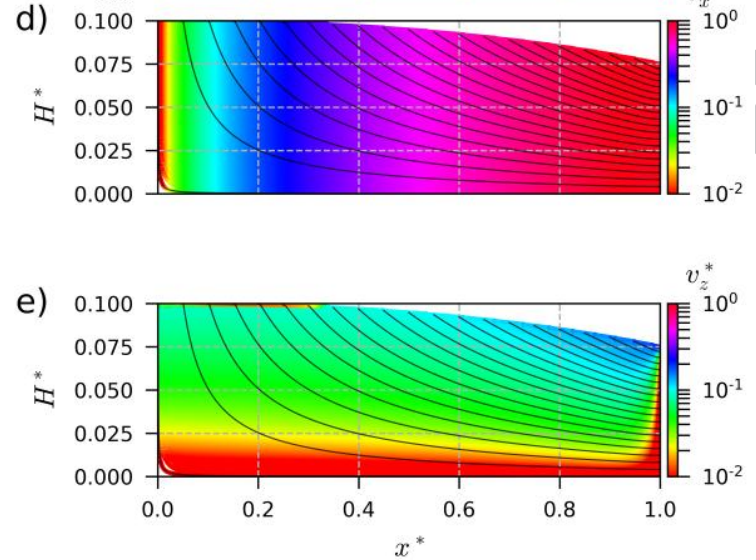
Case $\mathrm{H}: C_{H}=0.5$ and $C_{R}=1$

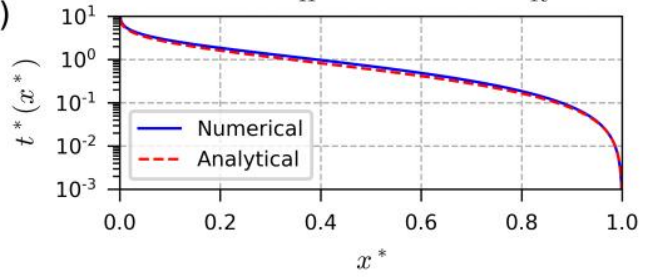

b)
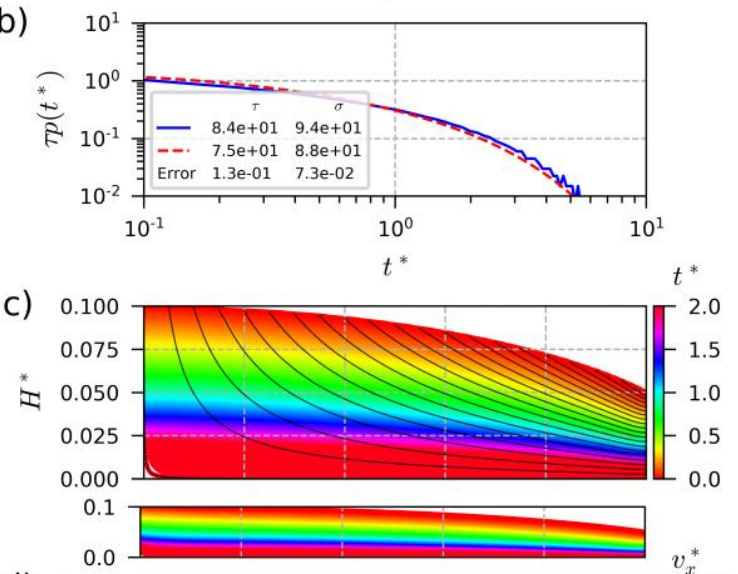

d) 0.100
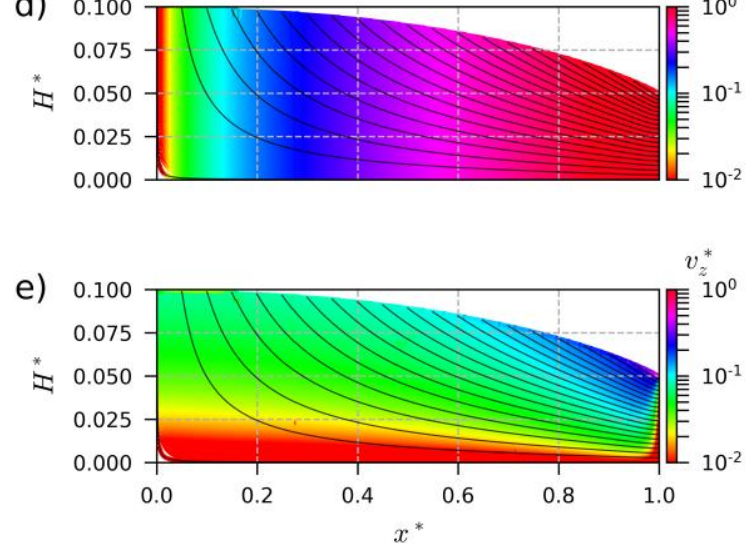
Case I: $C_{H}=0.1$ and $C_{R}=1$

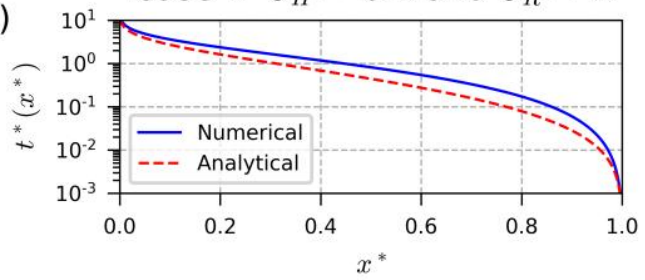

b)
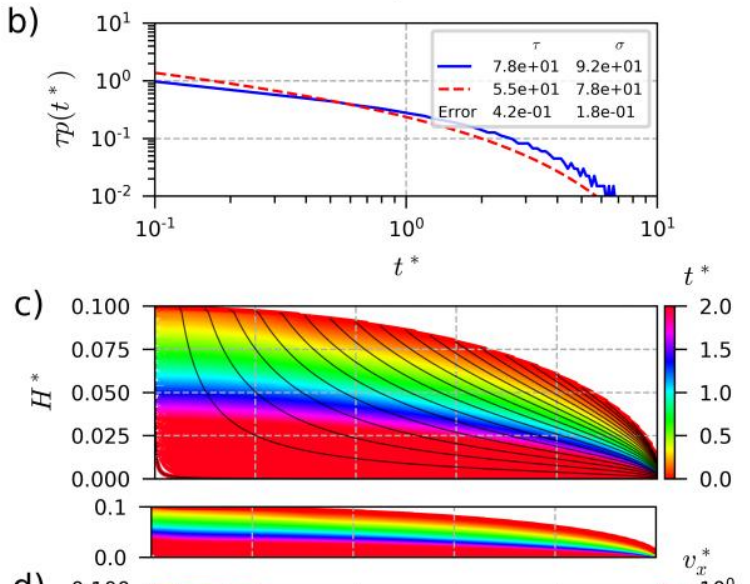

d) 0.100
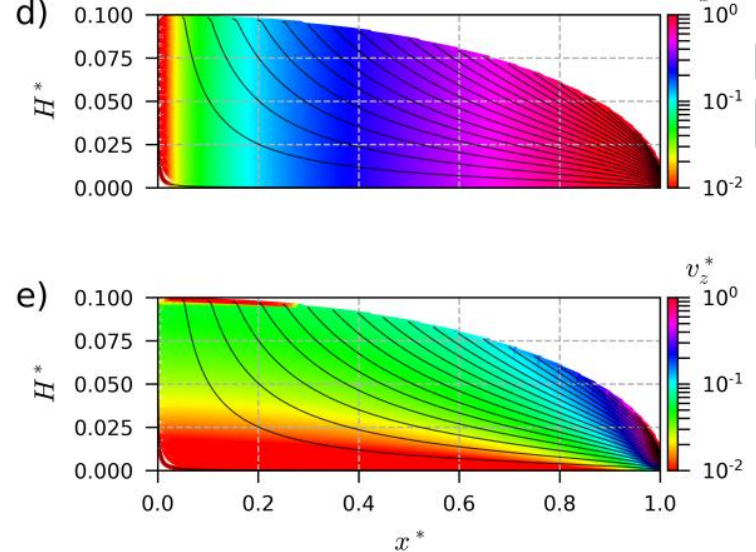
Residence Time Distributions in non-uniform aquifer recharge and thickness conditions

\section{Graphical abstract}

Deviation of the RTD variance to the exponential model and aquifer morphologies

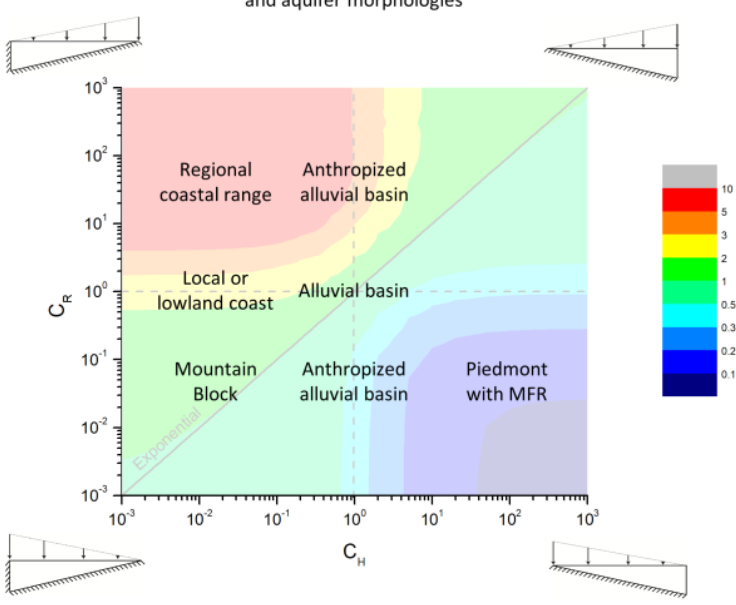


Residence Time Distributions in non-uniform aquifer recharge and thickness conditions

\section{Highlights:}

- A depth-integrated semi-analytical approximation for residence times is proposed

- The solution is validated by 2D discretized flow simulations with high consistency

- Compensating recharge and thickness trends lead to an exponential distribution

- Non-compensating effects lead to nontrivial and variedly shaped distributions

- Distributions shape may be Gamma-like or truncated power-law-like, amongst others 